\title{
Risk Assessment of Pedestrian Evacuation under the Influence of Fire Products
}

\author{
Chenghao Ye, ${ }^{1,2}$ Yuechan Liu $(1),{ }^{1}$ and Chao Sun ${ }^{1}$ \\ ${ }^{1}$ School of Measurement and Communication Engineering, Harbin University of Science and Technology, Harbin 150080, China \\ ${ }^{2}$ School of Resources and Civil Engineering, Northeastern University, Shenyang 110819, China \\ Correspondence should be addressed to Yuechan Liu; liuyuechan@hrbust.edu.cn
}

Received 28 July 2020; Revised 21 August 2020; Accepted 13 September 2020; Published 6 October 2020

Academic Editor: Stefan Balint

Copyright ( 12020 Chenghao Ye et al. This is an open access article distributed under the Creative Commons Attribution License, which permits unrestricted use, distribution, and reproduction in any medium, provided the original work is properly cited.

Traditional methods are using FDS and Pathfinder for numerical simulation of fire evacuation and do not consider the impact of fire products on pedestrians, which will lead to erroneous evacuation results. In order to explore the impact of fire products on pedestrian evacuation when a fire occurs in a building, the pedestrian evacuation risk assessment results are closer to the actual situation. By establishing a full-scale model based on the pedestrian evacuation speed coefficient, a numerical simulation of the evacuation of pedestrians under the influence of fire products is carried out, and the influence of spray intensity and smoke exhaust rate on pedestrian evacuation is analysed at the same time. The results show that, compared with traditional methods, the fire evacuation model based on the evacuation speed coefficient can better reflect the evacuation effect of the real fire scene. At the same time, adding spray and smoke exhaust devices can give pedestrians more time to escape.

\section{Introduction}

With the development of computer technology and the indepth study of human behavior and psychology, researchers gradually began to widely use computers to directly simulate the movement state of people in buildings and established a large number of evacuation models. The evacuation efficiency of a fire is affected by many factors, not only to consider the differences between individuals in the evacuation process, such as cognitive level [1], physiological conditions, mobility, psychological pressure, and other factors [2] impact on the speed of pedestrian evacuation. In addition, the structural details of the building such as evacuation exit conditions [3, 4], emergency lighting system $[5]$, escalators and stairs $[6,7]$, etc. will also affect the evacuation of personnel to varying degrees. In addition, there are many related in-depth and meticulous researches on different groups and locations of fires. Through the use of computer simulations, a variety of models have been established to study the laws and characteristics of personnel evacuation behavior, making this research direction continue to mature. research on the evacuation of personnel during the fire started earlier in foreign countries. As early as 1909, the United States published a research report on personnel evacuation behavior [8]. In the early 1930s, the National Bureau of Standards conducted evacuation simulation studies in normal environments and fire drill environments. Japanese scientist Togawa, British scientist Melink, Booth, etc., through video data and related fire records, based on a large number of observations, summed up the empirical calculation formula for time in the evacuation process [9]. "The behavior of people in Fires" written by the British scientist Wood through a large number of fire case investigations is regarded as a representative work in the field of human fire behavior [10]. In the theoretical study of personnel evacuation, Henderson first proposed the macro model of personnel evacuation [11]. In this article, the movement behavior of pedestrians is similar to the flow of gas or fluid. German traffic flow expert Helbing and his colleagues based on Lewin's concept of social power and improved it on the basis of Henderson's fluid dynamic equations and jointly constructed a social power pedestrian traffic flow model in 1995. Subjective expectations, the interrelationships between people, the interaction between 
people and the environment, the psychological reactions of personnel, and other forces are quantified, which is described by the concept of social force. In 1986, U. Frisch, B. Hasslacher, and Y. Pomeau collaborated and proposed a lattice gas model. The state variables such as space, time, and speed and position of the model are discrete, so the speed of calculation is increased. Von Neumann et al. proposed the cellular automaton in 1948. Since the time, space, and state in the model are discrete variables, this highly discrete calculation can perform high-speed simulation operations for high-performance computers. Moreover, it can easily reproduce different complex phenomena in fire or self-organization, mutual attraction, and chaos in the process of dynamic evolution of fire and has strong ability to simulate various physical systems and natural phenomena.

In recent years, with the continuous occurrence of fires, domestic research on the evacuation simulation model of people in the process of fire has been increasingly emphasized, and domestic units at all levels have begun to gradually carry out research on all aspects of fires. Among them, Northeastern University Chen and others have comprehensively studied the problems of personnel evacuation in fires, including the general evacuation behavior characteristics and disaster avoidance strategies of people during fires [12-14] and established personnel emergency in major accidents. The evacuation model [15], the simulation model of human evacuation behavior after a fire in a large public building [16], and the simulation model of personnel evacuation based on virtual reality technology [17]. Workers such as Founder and Lu of the City University of Hong Kong established a space grid evacuation model $[18,19]$. Wuhan University Founder and others have developed the evacuation simulation software for high-rise buildings [20]. After establishing the State Key Laboratory of Fire Science, the University of Science and Technology of China gradually began to organize related research: Song et al. quantified and optimized friction and repulsion by combining existing social force models based on the classic cellular automaton model The calculation rules of force improve the efficiency of calculation by optimizing continuous model and discrete model and improve the quantitative description of repulsive force and friction force, which greatly improves the calculation speed and saves its accuracy and improves the cell Automaton model [21].

On the basis of the existing cellular automaton traffic flow model and pedestrian flow model, Yang proposed a basic model for simulating the escape of people in a fire [22]. By introducing the concept of "total hazard map," Good simulation of the intelligence of personnel and the role of fire scenes makes the model more reasonable and convenient in determining the escape route of personnel. In addition, he also developed a microscopic discrete evacuation model of personnel behavior based on cellular automata theory [23], so that the individual characteristics of each evacuee can be simulated. Zheng et al. simulated the dynamics of pedestrian evacuation based on cellular automata-based underground flood diffusion [24]. Choi and Chi studied the optimal route selection model for fire evacuation based on hazard prediction data [25].
Sun and Wang conducted relevant research on the simulation of the evacuation preparation time and exit width on the evacuation of people [26]. In addition, they and other scientists conducted a major fire in urban high-rise buildings under the leadership of academician Fan Weicheng, the project expert team leader and research on key basic issues of prevention and control. Secondly, there are also many related researches on individual differences and related phenomena in the process of fire, such as psychological factors [27], cognitive level [1], group phenomena [28], the effect of indicators on personnel evacuation during the fire [29] and research on other aspects. At present, the main scenes of the main personnel evacuation research are: research on the school gymnasium [30], teaching building [31, 32], etc. In addition, there are also many researches on the impact factors of the fire process on the fire environment on people, including smoke regulation [33], smoke toxicity [34], and many other aspects.

According to relevant statistics of the American Fire Protection Association, deaths in fires are mainly caused by poisoning and suffocation, with a general proportion of $80 \%$ from poisonous smoke, 13\% from high temperature, and 7\% from other causes [35]. Therefore, when assessing the risk of building fires, it is very necessary to consider the evacuation of pedestrians under the influence of fire products. Many scholars have conducted research on this. Sun et al. [36] conducted numerical simulation studies on the spread and development of fire and the evacuation of pedestrians for teaching buildings; Song et al. [37] conducted fire control operations and pedestrians safety in the terminal building; Quantitative simulations were made; Chen [38] conducted a fire dynamic evolution process and numerical simulation of pedestrians evacuation of the subway station and gave indicators for judging the safe evacuation of pedestrians; Liu et al. [39] carried out pedestrians under fire in high-rise buildings Evacuation research; Li and Zhang [40] conducted a fire simulation and safety evacuation study in a connected dormitory building using the fire simulation software FDS and the pedestrians evacuation software Pathfinder.

Most of the previous researches used the fire dynamic simulation software FDS and the personnel evacuation software Pathfinder together, but did not connect the fire products with the evacuation. When conducting the evacuation research under fire conditions, the fire products did not have any impact on the pedestrians in the evacuation, which would lead to false evacuation conclusions. In order to reduce the error caused by traditional method, make the evacuation result closer to the real scene. Therefore, the author intends to use FDS and Pathfinder to conduct simulation research on evacuation of people under the influence of fire products and provide certain guidance for pedestrian evacuation risk assessment of building fires based on the simulation results.

\section{Theoretical Framework}

As shown in the figures, Figure 1 is the traditional method. By setting three types of detectors at the exit of the fire dynamic simulation software FDS, the shortest time for the 


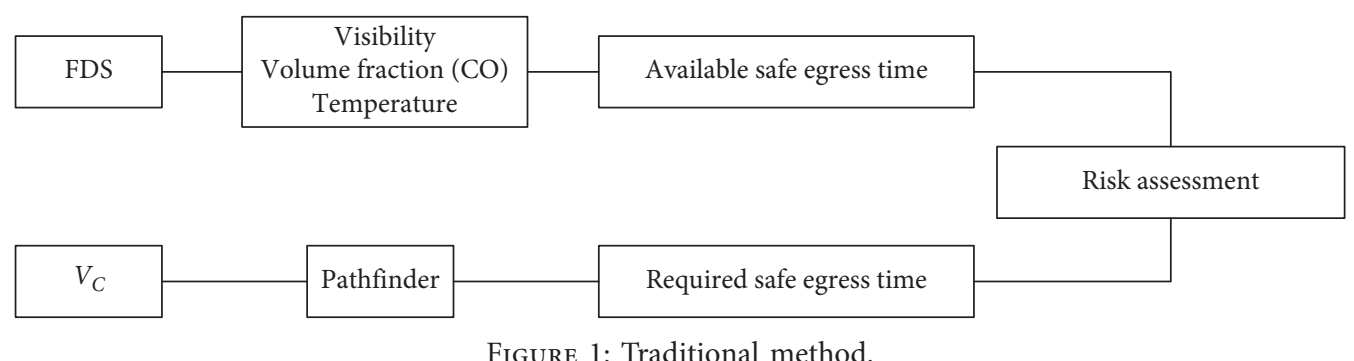

three types of sensors to reach the specified critical hazard value is regarded as Available Safe Egress Time (ASET), in the pedestrian evacuation software Pathfinder; $V_{c}$ represents the pedestrians to evacuate at a fixed walking speed. When the pedestrians evacuate to the exit, the evacuation time of the pedestrian is regarded as the Required Safe Egress Time (RSET). Although comparing ASET and RSET to assess whether the pedestrian is safe to escape, this method does not consider the impact of fire products on pedestrian. Pedestrians always escape at a fixed speed $V_{c}$ during the evacuation process, which is inconsistent with the actual situation. Figure 2 shows the proposed method in this paper. As shown in the figure, different from the previous model establishment, in this paper, BIM software Revit is used to establish the research model, which can be directly imported into FDS and Pathfinder, and the authenticity and restoration degree of the model is much higher than previous modeling methods. In FDS, $\mathrm{CO}$ volume fraction, $\mathrm{CO}_{2}$ volume fraction, $\mathrm{O}_{2}$ volume fraction, and temperature are used as ASET, and the ASET is refined. The refined ASET can get the injury status of the person. Use visibility, $\mathrm{CO}$ volume fraction, and temperature as indicators that affect the evacuation of pedestrians. By converting the three into Evacuation Speed Coefficient and importing the Speed Modifier that comes with Pathfinder, the pedestrian evacuation speed is $V_{t}$ at this time, which means that during the evacuation process, pedestrians' speed will change with the change of time. It can be considered that the fire products have an impact on the evacuation of people. By getting RSET in Pathfinder and comparing it with the refined ASET, we can get the four states of pedestrians (No injury, Minor injured, Seriously injured, and Dead).

\section{Materials Method}

3.1. Composition and Influence of Fire Products. The fire products are mainly divided into fire smoke and hightemperature hot plume. These products will reduce the physiological movement ability of pedestrians, affect the choice of escape routes, and even affect the nervous system of pedestrians, causing pedestrians to make wrong judgments during the evacuation process. The hazards of fire products are as follows:

(i) The shading of smoke: Combustible materials will produce a large number of solid particles and other gas-phase products and associated droplets during the combustion decomposition process, which are collectively referred to as flue gas. The accumulation of smoke will result in reduced visibility, which will affect pedestrians' field of vision and negatively affect the evacuation of pedestrians.

(ii) The toxicity of smoke: Once pedestrians in the fire inhale toxic and harmful fumes, some mechanisms and functions of body organs will be affected. If inhaled for a long time, they may even cause serious injury or death. The most significant effects of fire smoke on the human body are $\mathrm{CO}$ and $\mathrm{CO}_{2}$. The former weakens the binding of hemoglobin to $\mathrm{O}_{2}$, resulting in insufficient $\mathrm{O}_{2}$ content in the blood and insufficient support; the latter affects the respiratory rate and depth of the human body, causing pedestrians to inhale toxic and harmful gases faster. In the fire scene, the rapid consumption of oxygen during the fire will also cause suffocation and other situations, which will hinder the escape. The effects of different volume fractions of $\mathrm{CO}, \mathrm{CO}_{2}$, and $\mathrm{O}_{2}$ on the human body are shown in Tables 1-3.

(iii) High-temperature hot plume. High-temperature thermal plumes mainly affect the circulatory system and nervous system of the human body. When the human body is exposed to high temperature for a long time, it will cause the skin blood vessels to dilate, and a lot of sweating will condense the blood, resulting in a rapid heartbeat, increased blood pressure, abnormal co-ordination and accuracy of human movements, resulting in reduced brain reaction speed and attention. Under normal circumstances, the tolerance of pedestrians to different temperatures is shown in Table 4.

3.2. Fire Product Impact Function. Zhu [41] believes that the speed of pedestrian evacuation in a fire is mainly affected by visibility, $\mathrm{CO}$, and flue gas temperature, and can be divided into the following three aspects:

(i) Visibility: The visibility of the fire, which is mainly caused by the smoke volume fraction, affects the field of vision of the pedestrians during the evacuation process, thereby affecting the escape speed of the pedestrians.

(ii) CO: The impact on the body organs of pedestrians is mainly reflected in the toxicity of anesthesia and stimulation of toxicity. Long-term inhalation may cause serious injury or death. 


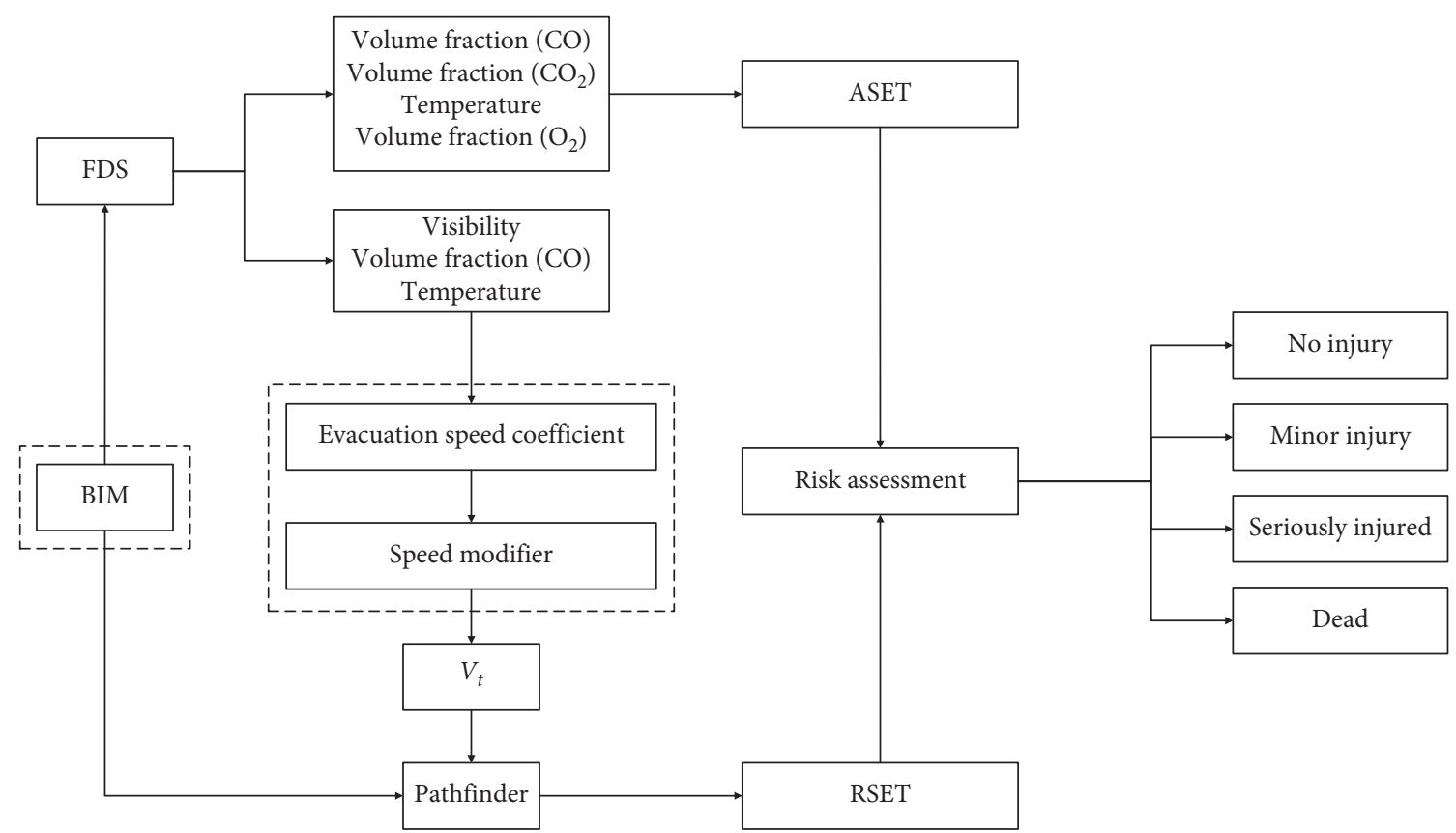

Figure 2: The proposed method in this paper.

TABle 1: Effects of CO on the human body.

\begin{tabular}{lc}
\hline CO volume fraction (\%) & Human reaction symptoms \\
\hline 0.01 & Little effect on human body \\
0.05 & 1 h exposure has little effect on the human body \\
0.1 & Discomfort, headache, vomiting after 1 hour of exposure \\
0.5 & Severe headache, risk of death after 20-30 min \\
1.0 & Lose consciousness several times after breathing and die after 1-2 min \\
\hline
\end{tabular}

TABLE 2: Effects of $\mathrm{CO}_{2}$ on the human body.

\begin{tabular}{lc}
\hline $\mathrm{CO}_{2}$ volume fraction (\%) & Human reaction symptoms \\
\hline 0.55 & The human body will not produce any symptoms within $6 \mathrm{~h}$ \\
$1-2$ & Cause discomfort \\
5 & Feeling unable to gasp, causing poisoning within 30 minutes \\
$7-10$ & Lose consciousness within minutes to death \\
\hline
\end{tabular}

TABLE 3: Effects of $\mathrm{O}_{2}$ on the human body.

\begin{tabular}{lc}
\hline $\mathrm{O}_{2}$ volume fraction (\%) & Human reaction symptoms \\
\hline 19.5 & The body begins to show bad physical reactions \\
$12-15$ & Shortness of breath, headache, dizziness, slow movements \\
$10-12$ & Nausea and vomiting, inability to move or even paralysis \\
Less than 6 & Within 6-8 min, pedestrians will die \\
\hline
\end{tabular}

TABLE 4: Effects of high temperature on the human body.

\begin{tabular}{lc}
\hline Environment temperature $\left({ }^{\circ} \mathrm{C}\right)$ & Endure time $(\mathrm{min})$ \\
\hline 50 & $>60$ \\
70 & 60 \\
$100-130$ & 15 \\
$200-250$ & 5 \\
\hline
\end{tabular}

(iii) Temperature: Affect the physical function of pedestrians, make pedestrians feel hot, dizzy and dizzy, and produce nervousness.

Zhu [41] introduced the concept of equivalent speed coefficient, quantified the impact of the 3 products on the human body, and introduced visibility coefficient $f(v)$, CO influence 
coefficient $f(c)$, and temperature influence coefficient $f(\theta)$. The product of these 3 coefficients represents the total effect of fire products on the rate of human evacuation [41].

$$
v=v_{0} \times f(v) \times f(c) \times f(\theta) .
$$

Theorem 1. $v$ is the walking speed of the person during evacuation, $m / s ; v_{0}$ is the reference speed of the person taking the walking speed of the person when there is no fire, which is $1.2 \mathrm{~m} / \mathrm{s}$ in this study.

3.3. Visibility Influence Function. At the $12^{\text {th }}$ International Conference on Performance Based Codes and Fire Safety Design Methods, Karl $f$ from Lund University [42] summarized data on the speed of pedestrians walking in smoke based on 10 different empirical formulas and provided a representation of walking. The relationship between the speed and visibility functions, the visibility impact coefficient and visibility are as follows:

$$
f(v)=\min (1, \max (0.2,1-0.34(3-\text { VIS }))) .
$$

Theorem 2. VIS represents the visibility of pedestrians during evacuation, $m$.

Figure 3 shows the influence of visibility on the coefficient of evacuation. As shown in Figure 3, the curve varies linearly between $0.6 \mathrm{~m}<\mathrm{VIS}<3 \mathrm{~m}$. When VIS $>3 \mathrm{~m}$ or VIS $<0.6 \mathrm{~m}$, the visibility coefficient is invariable, always 1 or 0.2 .

3.4. CO Influence Function. Zhu [41] fitted the formula of the effect of $\mathrm{CO}$ on human body speed measured by different volume fractions of Milke [43] as a formula. And the function of $\mathrm{CO}$ volume fraction, the expression is as follows:

$$
f(c)= \begin{cases}1, & (p<0.1), \\ 1-(0.2125+1.788 p) p t, & (0.1 \leq p<0.25), \\ 0, & (p \geq 0.25) .\end{cases}
$$

Theorem 3. $p$ is the volume fraction of $C O, \%, t$ is the exposure time, min.

Zhu [41] thinks that when the co volume fraction of smoke is less than $0.1 \%$, the evacuation speed to the human body can be neglected. When the volume fraction of the smoke reaches $0.25 \%$, it can cause serious harm to the pedestrians, resulting in the evacuation speed down to 0 at this time, and the pedestrians lose their power of action.

3.5. Temperature Influence Function. Zhu [41] believes that the effects of high-temperature plumes on human body can be divided into 3 stages:

(i) When the temperature $\theta<30^{\circ} \mathrm{C}$ is perceived by the human body, it can be considered that the

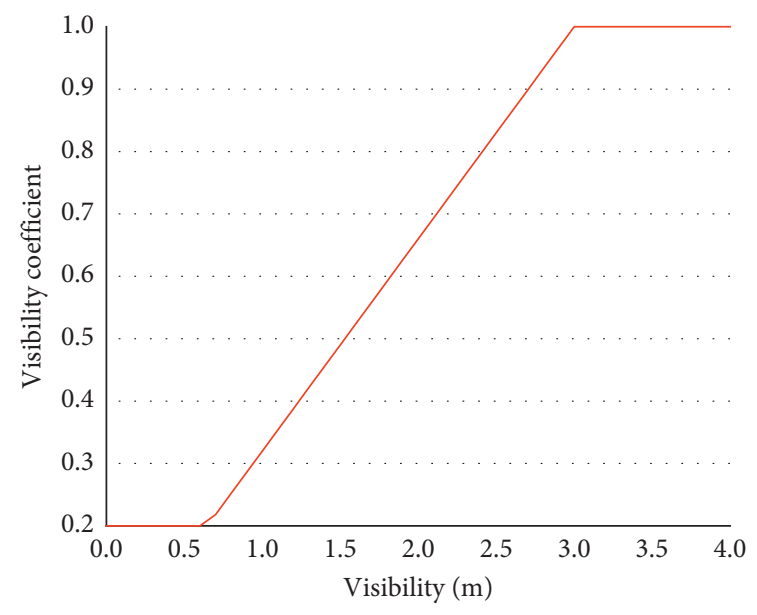

FIGURE 3: Impact of visibility on evacuation coefficient.

temperature has no effect on the evacuation speed of the person, at this time $f(\theta)$ is always equal to 1 .

(ii) When the temperature sensed by the human body is $30^{\circ} \mathrm{C}<\theta<60^{\circ} \mathrm{C}$, during this time period, the human body senses the temperature rise, stimulating the pedestrians to escape from the fire quickly; at this time, the temperature has a positive effect on the speed of evacuation of the pedestrians.

(iii) When the temperature sensed by the human body is $\theta>120^{\circ} \mathrm{C}$, the evacuation speed of the pedestrians is gradually reduced by the temperature until the pedestrians lose their ability to move. At this time, the temperature has a negative effect on the evacuation of the pedestrians.

The expression is as follows:

$$
f(\theta)= \begin{cases}1, & \left(\theta_{s} \leq \theta_{c r 1}\right), \\ \frac{\left(v_{\max }-1.2\right)\left(\theta_{s}-\theta_{c r 1} / \theta_{c r 2}-\theta_{c r 1}\right)^{2}}{v_{0}}+1, & \left(\theta_{c r 1}<\theta_{s} \leq \theta_{c r 2}\right), \\ \frac{v_{\max }}{1.2}\left[1-\left(\frac{\theta_{s}-\theta_{c r 2}}{\theta_{d}-\theta_{c r 2}}\right)^{2}\right], & \left(\theta_{c r 2}<\theta_{s} \leq \theta_{d}\right) .\end{cases}
$$

Theorem 4. $\theta_{s}$ is the actual temperature of the fire site, ${ }^{\circ} \mathrm{C} ; \mathrm{v}$ is the maximum escape speed, $\mathrm{m} / \mathrm{s}$, generally 4 ; $\theta_{c r 1}$ is the temperature that pedestrians feel uncomfortable, ${ }^{\circ} \mathrm{C}$, take $\theta_{c r 1}=30 ; \theta_{c r 2}$ is the temperature that causes harm to pedestrians, ${ }^{\circ} \mathrm{C}$; take $\theta_{c r 2}=60$; $\theta_{d}$ is the temperature that causes serious injury to pedestrians, ${ }^{\circ} \mathrm{C}$; take $\theta_{d}=120$.

Figure 4 represents the influence of temperature on the evacuation coefficient of pedestrians. It can be seen from the Figure 4 that when the temperature $\theta<30^{\circ} \mathrm{C}$, the temperature influence coefficient $f(\theta)$ is always 1 ; when the temperature $\theta=60^{\circ} \mathrm{C}$, the temperature influence coefficient $f(\theta)_{\max }=3.333$; when the temperature $\theta>120^{\circ} \mathrm{C}$, the temperature influence coefficient $f(\theta)$ is always 0 . 


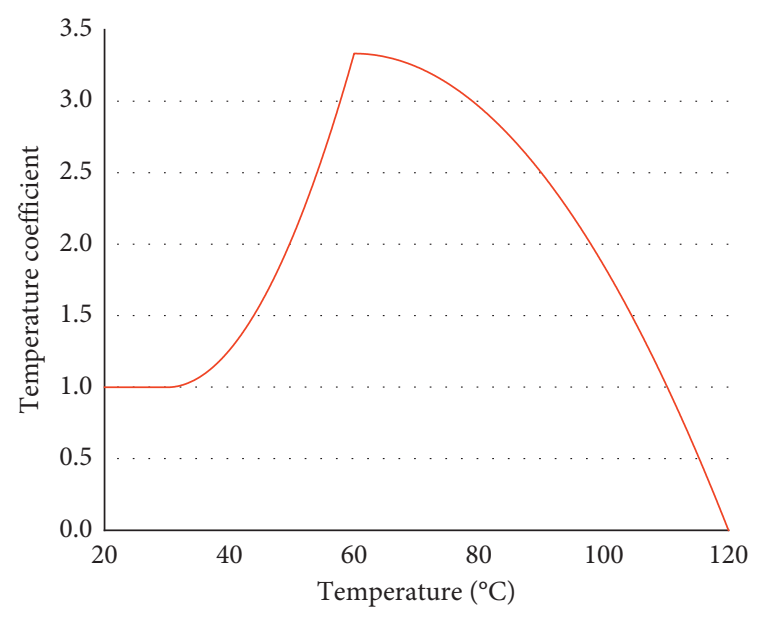

Figure 4: Impact of temperature on evacuation coefficient.

3.6. Consider the Numerical Simulation of Evacuation under Fire Products. FDS is a simulation software specially designed to create fire scenarios and view the evolution process of fire dynamics. It allows users to view the results of smoke spreading and fire spreading during the process of fire. Using the software, a building fire model can be obtained, as shown in Figure 5. The model is a full-scale fire model on the first floor of a building, with a total length of $84.0302 \mathrm{~m}$, a total length of $20 \mathrm{~m}$, and a height of $4 \mathrm{~m}$.

The fire source is located in a room. Figure 6 shows a schematic diagram of 23 regions in the fire model. 23 sensors divide the corridor into 23 zones. Each region has temperature sensors, CO sensors, visibility sensors, and sprinkler sensors, so as to output the result of fire products in each region. At the same time, the $\mathrm{CO}$ sensor, $\mathrm{CO}_{2}$ sensor, temperature sensor, and $\mathrm{O}_{2}$ sensor are 4 kinds of sensors, which are mainly used for the calculation of safe evacuation time. The height is $1.7 \mathrm{~m}$., and the specific fire parameters are shown in Table 5.

Pathfinder is the evacuation software based on evacuation dynamics. By setting the corresponding parameters (walking speed, shoulder width, outlet selection, etc.) for each escaping pedestrians in the group, and setting up the escape mode of pedestrians, virtual evacuation of pedestrian movement is simulated. In the Pathfinder 2019, a function of regional pedestrian speed modifier is added, as shown in Figure 7 , where the initial value is 1 . The initial evacuation speed of a representative, that is, the speed coefficient, corresponds to different values at different times. As time goes on, the fire products begin to affect the pedestrians, and the values continue to decrease; that is, the speed coefficient decreases, and the speed of the pedestrians starts to slow down until the speed is changed to 0 . It is used to establish evacuation model under the condition of fire product impact.

The fire model in the FDS can be directly imported into the Pathfinder. According to the location of the 23 detection regions in the FDS, 23 evacuation regions are manually divided into Pathfinder. Due to the fact that there is a certain delay in the fire control in the real fire scenario, in order to be

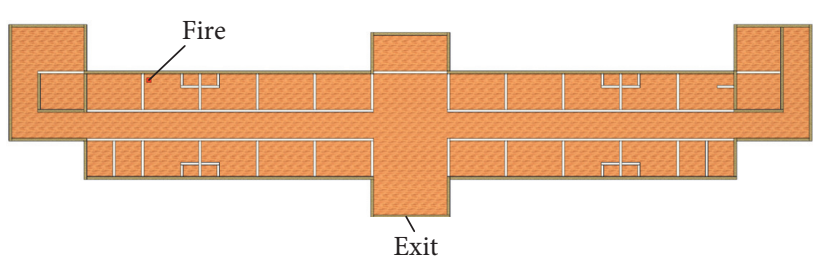

Figure 5: Building fire model.

closer to the actual evacuation situation, there are 5 kinds of response behaviors for different rooms. As shown in Figure 8 , the response delay time of different behavior pedestrians is shown in Table 6.

There are 6 kinds of working conditions for evacuation. There are different evacuations in different conditions, and each condition is divided into 2 scenarios, namely, Scenario 1 , without considering the effects of fire products; Scenario 2, taking into account the influence of fire products on the parameters of working conditions. The parameter settings of the 6 working conditions are shown in Table 7.

Assuming existence $0.1 \leq \mathbf{p}<0.25$, when $\mathbf{t}=\mathbf{t}_{0}$. At that time $\mathbf{p}=\mathbf{p}_{0}$; when $\mathbf{t}=\mathbf{t}_{\mathbf{i}+\mathbf{j}}$. At that time $\mathbf{p}=\mathbf{p}_{\mathbf{i}+\mathbf{j}}$. The relationship between time and volume fraction is shown in Table 8. Suppose the initial time is $\mathbf{t}_{\mathbf{i}}$. When $\mathbf{t}=\mathbf{t}_{\mathbf{i}}$, the person has been exposed to the volume fraction $\mathbf{p}_{\mathbf{i}}$ for $0.5 \mathrm{~s}$, then the speed state of the person at this moment is $\mathbf{f}(\mathbf{c})_{\mathbf{i}-1}$; When $\mathbf{t}=\mathbf{t}_{\mathbf{i}+1}$, the pedestrians enters the time $\mathbf{t}_{\mathbf{i}+1}$ at the state $\mathbf{f}(\mathbf{c})_{\mathbf{i}-1}$, the speed state of the pedestrians at this time is $\mathbf{f}(\mathbf{c})_{\mathbf{i}-1} \mathbf{f}(\mathbf{c})_{\mathbf{i}}$; In the same way, when $\mathbf{t}=\mathbf{t}_{\mathbf{i}+\mathbf{j}}$, the pedestrians enter the state $\mathbf{f}(\mathbf{c})_{\mathbf{i}-1} \mathbf{f}(\mathbf{c})_{\mathbf{i}} \ldots \mathbf{f}(\mathbf{c})_{\mathbf{i}+\mathbf{j}-2}$ at time $\mathbf{t}_{\mathbf{i}+\mathbf{j}}$; then the pedestrians speed state is $\mathbf{f}(\mathbf{c})_{\mathbf{i}-1} \mathbf{f}(\mathbf{c})_{\mathbf{i}} \ldots \mathbf{f}(\mathbf{c})_{\mathbf{i}+j-2} \mathbf{f}(\mathbf{c})_{\mathbf{i}+\mathbf{j}-1}$.

For the three kinds of fire product influence coefficients, the visibility influence coefficient and the temperature influence coefficient can be directly imported into Pathfinder, and for the $\mathrm{CO}$ influence coefficient, there are two variables, volume fraction and duration, which cannot be directly imported into Pathfinder, and the Theorem 4 needs to be modified.

Get the following formula:

$$
f(c)=1-(0.2125+1.788 p) p t .
$$

In this fire simulation calculation process, FDS records data about every $0.5 \mathrm{~s}$, the simulation time is $500 \mathrm{~s}$, and a total of 1001 data points; it can be considered that at the moment, the person has been exposed to the volume fraction for $0.5 \mathrm{~s}$, then the formula (5) change into

$$
f(c)=1-(0.2125+1.788 p) p \frac{0.5}{60} \text {. }
$$

When $\mathbf{p}<0.1$ or $\mathbf{p}>0.25$, there are only two states 1 or 0 . At this time, $\mathbf{p}$ has no relationship with the exposure time $\mathbf{t}$. It can be considered that the conversion method is applicable to the entire function expression.

3.7. Evacuation Results Analysis and Comparison. Figure 9 shows a comparison of speed coefficient curves between region 1 and region 22. As shown in Figure 9, the 


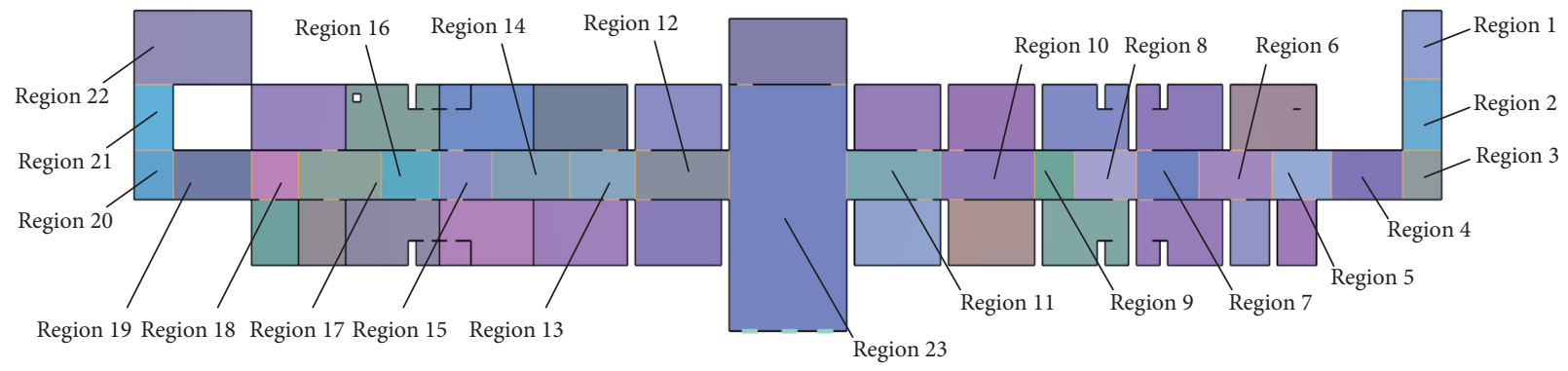

Figure 6: Evacuation region division.

TABLE 5: Fire parameters.

\begin{tabular}{lc}
\hline Fire parameter & Numerical value \\
\hline Fire heat release rate & $4 \mathrm{MW}$ \\
Spray intensity & $12 \mathrm{~L} / \mathrm{min}$ \\
CO sensor height & $1.75 \mathrm{~m}$ \\
Visibility sensor height & $1.7 \mathrm{~m}$ \\
Temperature sensor height & $1.65 \mathrm{~m}$ \\
Simulation time & $500 \mathrm{~s}$ \\
Mesh size & $0.5 \mathrm{~m} \times 0.5 \mathrm{~m} \times 0.5 \mathrm{~m}$ \\
\hline
\end{tabular}
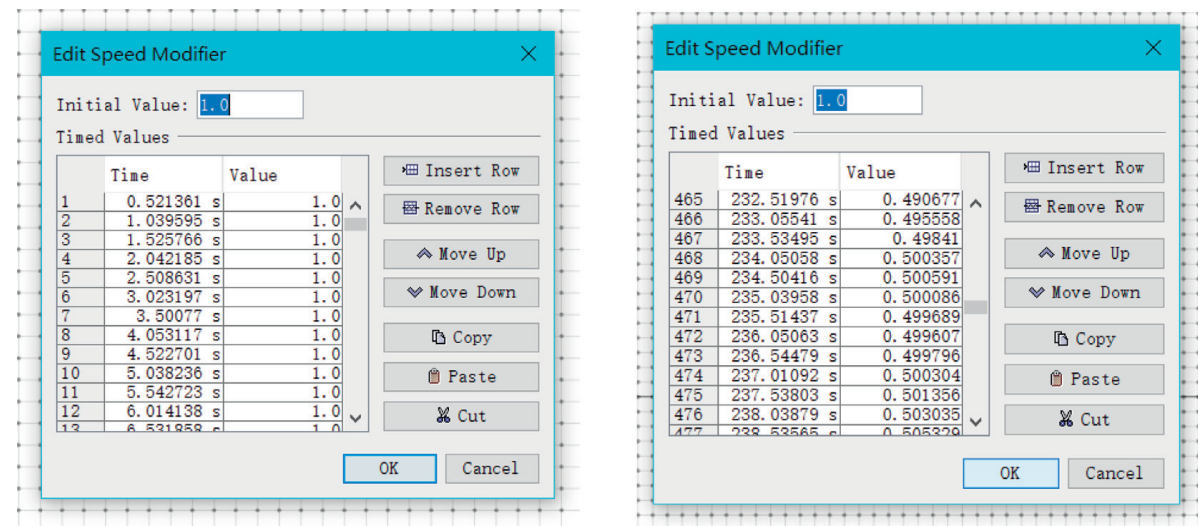

Figure 7: Speed modifier.

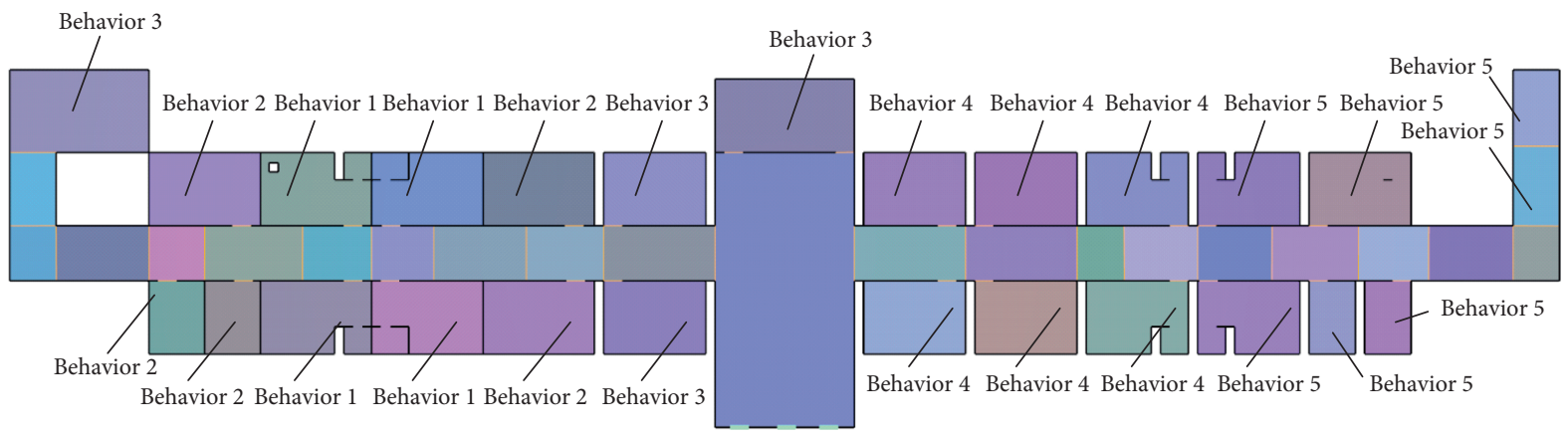

FIGURE 8: Different behaviors.

temperature has a positive effect on evacuation in the early stage of the fire, which dilutes the negative effects of visibility and $\mathrm{CO}$ on the human body. As the fire proceeds, $\mathrm{CO}$ reaches the dangerous point first, and the co speed coefficient returns to zero, leading to the total speed coefficient returning to zero. 
TABle 6: Pedestrians behavior.

\begin{tabular}{lr}
\hline Behavior & Response delay \\
\hline Behavior 1 & Response delay 20s \\
Behavior 2 & Response delay 25s \\
Behavior 3 & Response delay 30s \\
Behavior 4 & Response delay 35s \\
Behavior 5 & Response delay 40s \\
\hline
\end{tabular}

TABLE 7: Working condition.

Working condition

Working condition 1

Working condition 2

Working condition 3

Working condition 4

Working condition 5

Working condition 6

Number of pedestrians evacuated [pers]

200
300
400
500
600
700

TABLE 8: Relationship between time and volume fraction.

\begin{tabular}{lcc}
\hline Time & Volume fraction & Exposure time at this volume fraction \\
\hline$t_{0}$ & $p_{0}$ & $t_{1}-t_{0}$ \\
$t_{1}$ & $p_{1}$ & $t_{2}-t_{1}$ \\
$\ldots$ & $\ldots$ & $\ldots$ \\
$t_{i-1}$ & $p_{i-1}$ & $t_{i}-t_{i-1}$ \\
$t_{i}$ & $p_{i}$ & $t_{i+1}-t_{i}$ \\
$\ldots$ & $\cdots$ & $t_{i+j+1}-t_{i+j}$ \\
$t_{i+j}$ & $p_{i+j}$ & $t$ \\
\hline
\end{tabular}
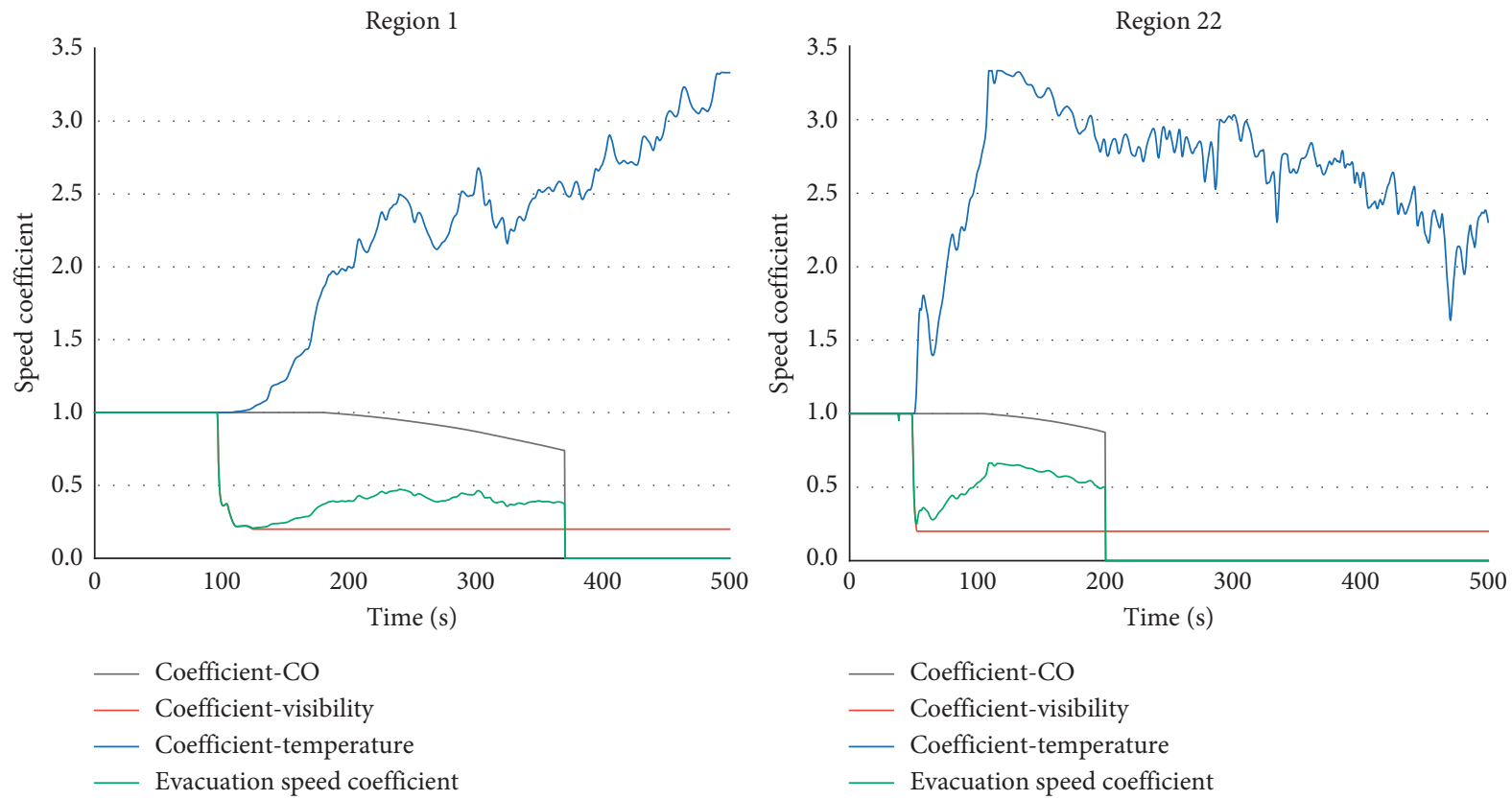

Figure 9: Comparison of speed coefficient curves between region 1 and region 22.

From Table 9, we can see that the evacuation time under the condition of considering the impact of fire products is significantly larger than the evacuation time without considering the impact of fire products. In the 2 scenarios, the maximum relative error is $60.69 \%$ when the evacuation is completed, and the smallest relative error is $39.59 \%$. For the 
TABLe 9: Pedestrians evacuation in two scenarios.

\begin{tabular}{lcccc}
\hline Number of pedestrians evacuated & Scenario 1 (s) & Scenario 2 (s) & Relative error (\%) & Whether all evacuations have been completed \\
\hline 200 & 101.0 & 162.3 & 60.69 & Yes \\
300 & 126.0 & 191.5 & 51.98 & Yes \\
400 & 147.8 & 223.5 & 51.21 & Yes \\
500 & 178.3 & 253.0 & 41.89 & Yes \\
600 & 200.8 & 280.3 & 39.59 & Yes \\
700 & 225.8 & 301.0 & - & No \\
\hline
\end{tabular}

In Scenario 2, when the number of evacuees was 700, 656 pedestrians completed evacuation at $301 \mathrm{~s}$, and 44 pedestrians did not escape because of the regional speed coefficient of 0 .

TABLE 10: ASET judgment index.

ASET
ASET1 The human body can withstand $1 \mathrm{~h}$, or the human body is injured, and some minor symptoms appear in the human body, which is
a minor injury
ASET2 The human body can withstand $15-30 \mathrm{~min}$, or the human body is seriously harmed, and the human body shows serious symptoms,
which is a serious injury

TABLE 11: ASET's quantitative indicators of fire products.

\begin{tabular}{lcccc}
\hline ASET & Temperature $\left({ }^{\circ} \mathrm{C}\right)$ & $\mathrm{CO}(\%)$ & $\mathrm{CO}_{2}(\%)$ & $\mathrm{O}_{2}(\%)$ \\
\hline ASET1 & 60 & 0.1 & 2 & 19.5 \\
ASET2 & 100 & 0.25 & 5 & 12 \\
ASET3 & 175 & 1.0 & 10 & 6 \\
\hline
\end{tabular}

TABle 12: Available safe egress time.

\begin{tabular}{lcccc}
\hline ASET & Temperature $(\mathrm{s})$ & $\mathrm{CO}(\mathrm{s})$ & $\mathrm{CO}_{2}(\mathrm{~s})$ & \\
\hline ASET1 & 191.54 & 129.53 & 174.03 & $\mathrm{O}_{2}(\mathrm{~s})$ \\
ASET2 & 330.03 & 261.52 & 302.54 & 256.00 \\
ASET3 & - & - & - & 452.01 \\
\hline
\end{tabular}

safe evacuation of pedestrians depends on 2 characteristic time: one is the time needed for the fire to develop to the safety threat to the pedestrians, that is, Available Safe Egress Time (ASET), and the second is the time needed to evacuate to the safe region, that is, Required Safe Egress Time, RSET, so as to ensure that the pedestrians can evacuate safely. We must ask RSET < ASET because of the great difference between the evacuation results under the 2 scenarios. The author will re-quantify the target ASET of safe evacuation. For ASET's judgment, $\mathrm{CO}_{2}, \mathrm{O}_{2}, \mathrm{CO}$, and temperature are used to judge whether the pedestrians are safe evacuation targets. These indicators can have a certain degree of influence on human health, and for 3 kinds of ASET, combined with the influence degree of fire smoke and temperature on human body, the index of ASET is quantified in Tables 10 and 11.

Take the time when the 4 indicators reach the prescribed value, respectively, and take the shortest time as the corresponding available safe evacuation time ASET. According to the 4 sensors set at the doorway in the model, 4 indexes meet the prescribed value corresponding to the time Table 12 .
Therefore, it can be considered that ASET1 $=129.53 \mathrm{~s}$, ASET2 $=261.52 \mathrm{~s}$, and ASET3 are not found in the study. Therefore, it is not worth considering ASET3. It is worth noting that the risk index adopted by the speed coefficient is the same as that adopted by the ASET, but this may lead to different results. It may appear that when the ASET2 arrives, the pedestrians still have the power of action. The use of a single measuring point instead of the data of a single region may cause some errors for larger regions, but this is acceptable, and the optimization of errors is not considered in this paper. The evacuation time under 6 working conditions is compared with ASET1 and ASET2, and the degree of injury in 2 scenarios is studied, taking working conditions 1 (200 pedestrians) and working conditions 6 (700 pedestrians) as an example.

Figure 10(a) shows the evacuation of 700 pedestrians in 2 scenarios. It can be seen that when we get to ASET1 $=129.53 \mathrm{~s}$, there are 379 pedestrians left in Scenario 1 and 550 pedestrians in Scenario 2. At that time, the remaining number is in the condition of slight injury. As the evacuation proceeds, the pedestrians in Scenario 1 have been evacuated before ASET2, and the pedestrians have not 


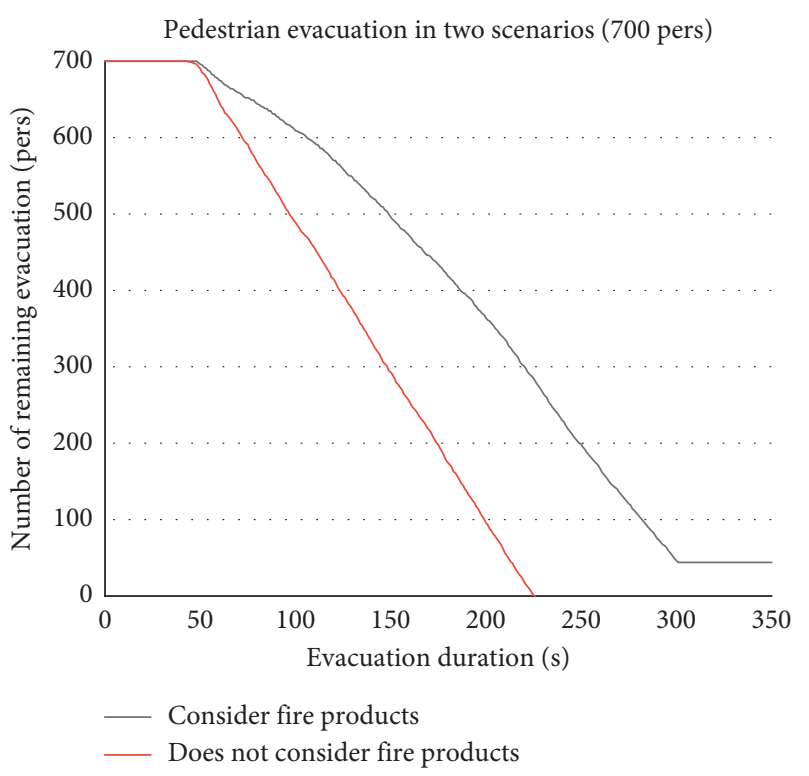

(a)

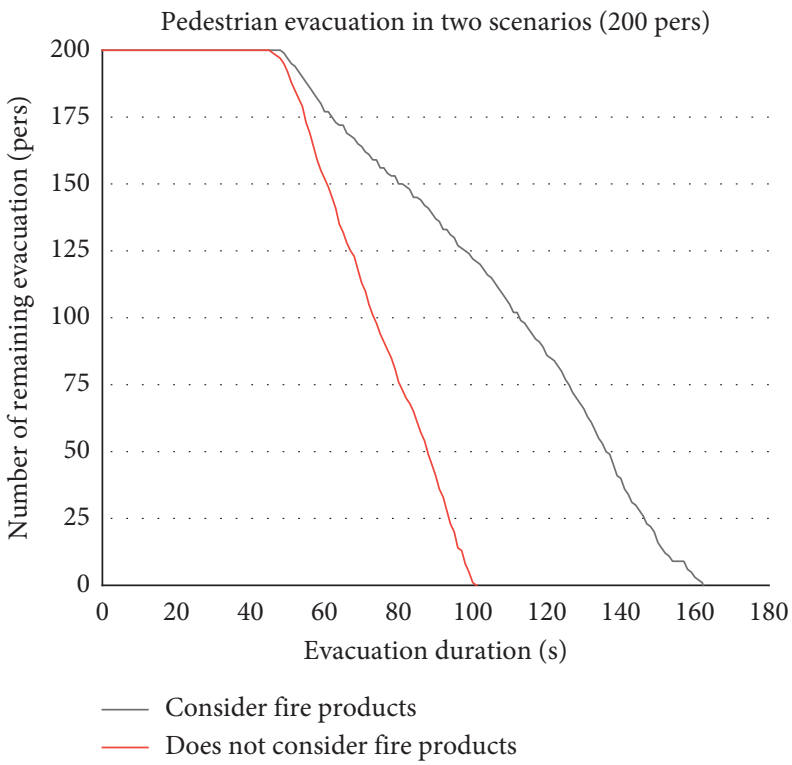

(b)

Figure 10: Comparison of pedestrian evacuation in different scenarios.

entered the serious injury state. When the Scenario 1 completes evacuation, there are still 281 pedestrians left in Scenario 2. When ASET2 $=261.52 \mathrm{~s}$ arrives, there are 162 remaining pedestrians in Scenario 2, when the remaining numbers get into serious injuries, but they still have the power to act. $=301 \mathrm{~s}$, when the speed coefficient of the Scenario 2 changed to 0 , which led to 44 pedestrians not completing the evacuation, it could be considered that the 44 officers lost their mobility due to excessive injury. Scenario 1 evacuated 700 pedestrians for $225.8 \mathrm{~s}$, Scenario 2 evacuated 656 pedestrians for $301 \mathrm{~s}, 44$ pedestrians failed to evacuate, and the difference is $75.2 \mathrm{~s}$.

Figure 10(b) is the evacuation of 200 pedestrians in 2 scenarios. When the evacuation of pedestrians in Scenario 1 is completed, there are still 121 pedestrians in Scenario 2. With the evacuation process continuing, when the ASET1 $=129.53 \mathrm{~s}$ reaches the scenario, the pedestrians in Scenario 1 have been evacuated, and the pedestrians have not been affected. However, 68 of the scenarios 2 have not yet completed the evacuation, and the 68 pedestrians have been slightly injured. At $=162.3 \mathrm{~s}$, the pedestrians in Scenario 2 completed evacuation, and there was only slight injury in the condition, without serious injury.

Through the analysis of the above 2 results, the evacuation time and the degree of injury are quite different in the 2 scenarios. In Case 6, for example, when the evacuation number is 700 , the pedestrians in Scenario 1 begin to evacuate completely without serious injury or loss of action. Even 44 of them stayed in the fire because of their loss of action. This is truer to the actual situation, because in the actual fire scenario, when the number of evacuees is large, it is easier for pedestrians to become unconscious due to heavy injuries. Therefore, it can be considered that the evacuation results under fire conditions are closer to the real situation than the traditional simulation results. A fire scenario can only correspond to an evacuation model, and the fire products have a direct impact on the evacuation of pedestrians.

3.8. Influence of Spray Intensity on Speed Coefficient. Zhao and Qian [44] research shows that different spray intensities can inhibit the temperature change in the fire field; Khoat et al. [45] analysed the fire characteristics after spray fire extinguishment in the cabin fire. During the fire extinguishing process, it is believed that the presence of spray has a significant effect on reducing the temperature of the smoke layer. Yang et al. [46] think that the spray intensity can prevent the visibility of the no fire source region from drastically decreasing, Wang et al.'s [47] numerical simulation showed that the CO volume fraction of the spray coverage region is higher than that of the no spray condition; Sun [48] used the fire simulation software FDS and fire test and found that within a certain range, the greater the spray intensity, the smaller the CO volume fraction in the chamber. It is found that within a certain range, the larger the spray intensity, the smaller the CO in the chamber. All the above studies prove that the spray intensity has an impact on the 3 kinds of analytical products. In order to explore the influence of spray intensity on the speed coefficient, 3 working conditions are set up in this paper. On the basis of the original model, a spray sensor is added at each $3.5 \mathrm{~m}$ height in the region, and a total of 23 sprinkler sensors are set up. The specific spray intensity settings are shown in Table 13.

A total of 4 representative regions were selected, of which 15 were located outside the fire room, adjacent to the fire region, 23,8 , and 1 gradually away from the fire region. The 
TABle 13: Spray intensity at different conditions.

\begin{tabular}{lr}
\hline Working condition & Spray intensity \\
\hline Working condition 1 & $0 \mathrm{~L} / \mathrm{min}$ \\
Working condition 2 & $6 \mathrm{~L} / \mathrm{min}$ \\
Working condition 3 & $12 \mathrm{~L} / \mathrm{min}$ \\
Mesh size & $0.5 \mathrm{~m} \times 0.3 \mathrm{~m} \times 0.5 \mathrm{~m}$ \\
\hline
\end{tabular}
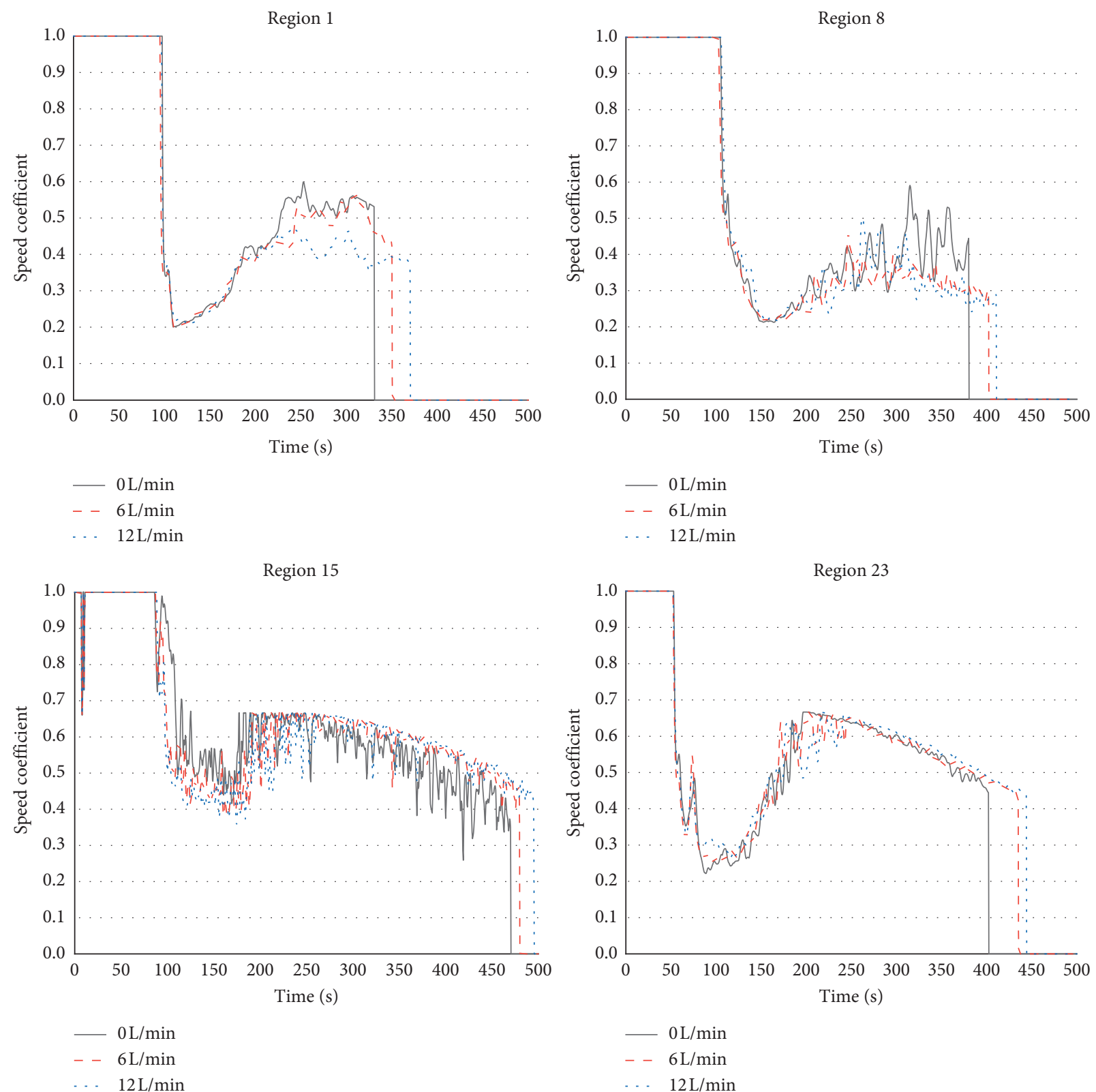

FIGURE 11: Effect of spray intensity on speed coefficient.

effect of spray intensity on the speed coefficient is shown in Figure 11. From Figure 11, it can be seen that the spray intensity has little effect on the speed coefficient, but with the increase of spray intensity, the time of curve zero return is postponed. That is, the time lag of pedestrian speed coefficient is 0 .
TABle 14: Smoke exhaust rate under different working conditions.

\begin{tabular}{lc}
\hline Working condition & Smoke exhaust rate \\
\hline Working condition 1 & $0 \mathrm{~m} / \mathrm{s}$ \\
Working condition 2 & $1 \mathrm{~m} / \mathrm{s}$ \\
Working condition 3 & $2 \mathrm{~m} / \mathrm{s}$ \\
Working condition 4 & $3 \mathrm{~m} / \mathrm{s}$ \\
Mesh size & $0.5 \mathrm{~m} \times 0.3 \mathrm{~m} \times 0.5 \mathrm{~m}$ \\
\hline
\end{tabular}



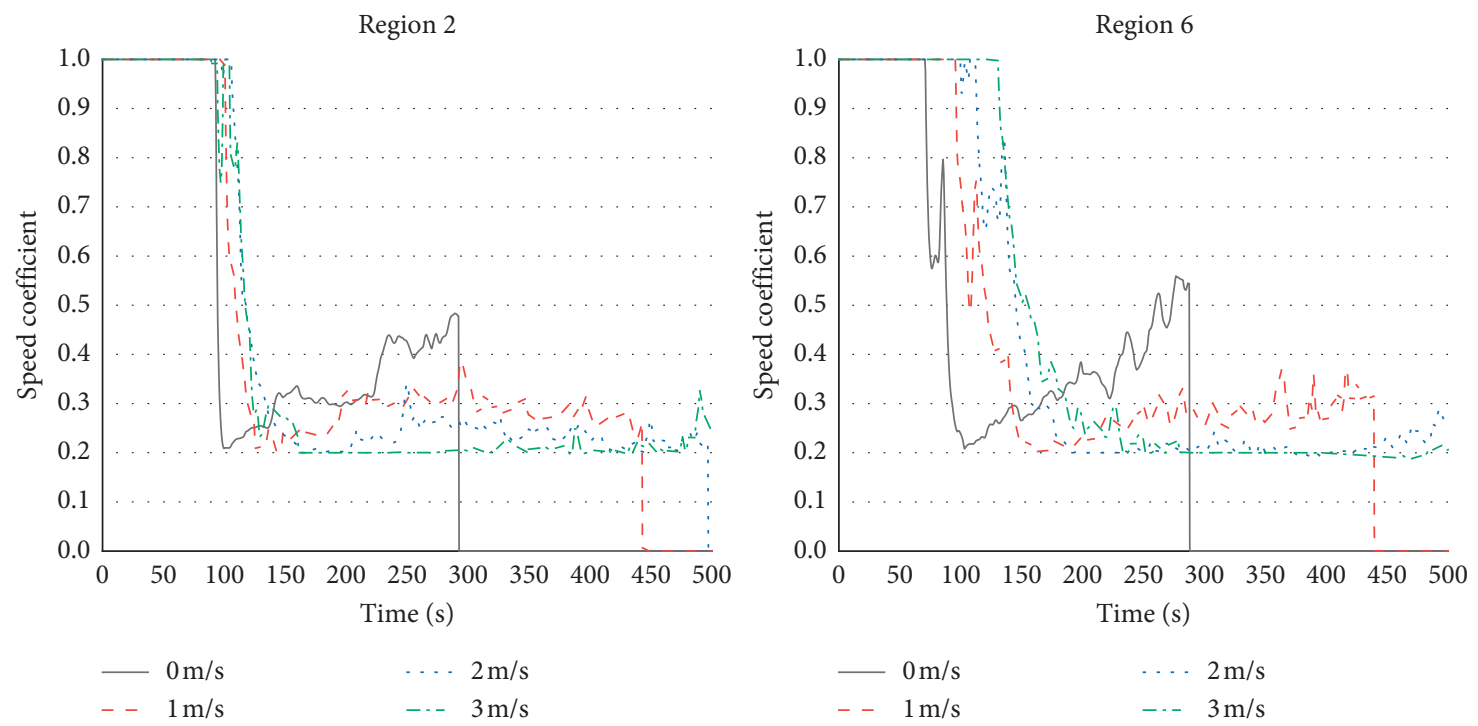

Region 10
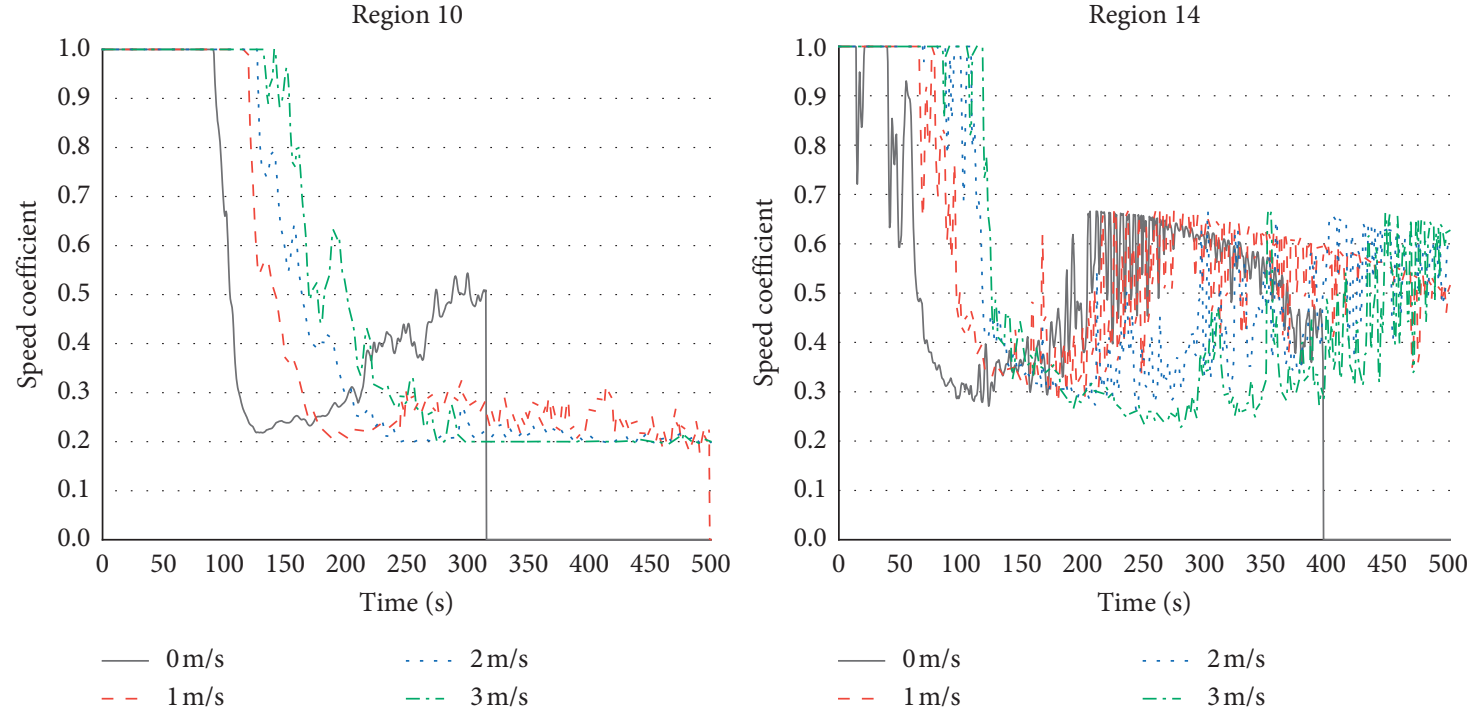

Region 18
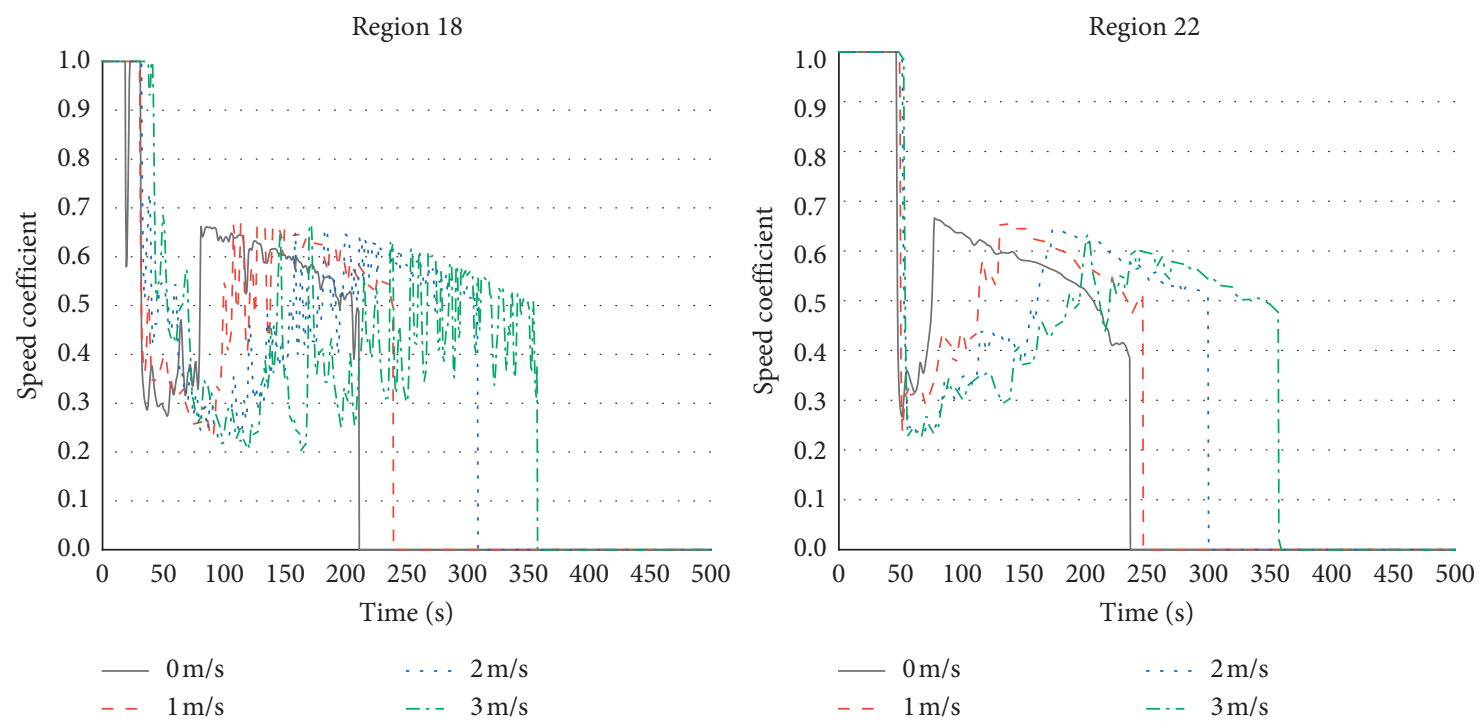

FIGURE 12: Effect of smoke exhaust rate on speed coefficient. 
For region 15, because the region is close to the fire region, in the middle and late fires, the greater the spray intensity, the greater the speed coefficient, while for region 1 and region 8 , in the middle of the fire, the greater the spray intensity, the speed coefficient. On the contrary, the speed coefficient is smaller. This is because, in this period of time, the most important indicator of spray influence is temperature. The higher the spraying intensity, the higher the temperature in the region, but the temperature always has a positive effect on the human body, stimulating pedestrians to accelerate away from the region.

3.9. Influence of Smoke Rate on Speed Coefficient. Wang et al. [49] research shows that mechanical exhaust can effectively reduce the highest temperature and the highest volume fraction of $\mathrm{CO}$ in the fire field and delay the beginning time of the smoke visibility. Zhu and $\mathrm{Li}$ [50] carried out the small size fire smoke simulation test and found that the exhaust efficiency has a certain effect on the temperature of the hot smoke layer. In order to explore the influence of smoke rate on the speed coefficient, 4 kinds of working conditions are set up in this paper. Due to the large number of detection regions, 6 regions were taken as comparison objects, and smoke exhaust ports were set up in the height of 22 regions, including region 22 , region 18 , region 14 , region 10 , region 16 , and region 2 . The length and width of smoke outlets were all $0.5 \mathrm{~m}$.

The smoke emission rate corresponding to different conditions is Table 14. As can be seen from Figure 12, smoke exhaust has a significant effect on the speed coefficient. In the middle of the fire, the speed coefficient decreases with the increase of exhaust gas rate. This is because the temperature has a positive effect on the human body at that time. The higher the smoke exhaust rate and the lower the temperature, the smaller the stimulating effect on the human body. The time lag of speed coefficient returning to zero is delayed, and the effect of smoke exhaust on speed coefficient is much better than that of spray.

3.10. Hospital Building Information Modeling. The Second Hospital of Medical University is called the Second Affiliated Hospital of Harbin Medical University. Its outpatients building has 7 floors, including 6 floors above ground and 1 floor underground. According to the on-site inspection, the -1 st to 4 th floors are mostly outpatients' rooms, the 5th to 6th floors are mainly ward regions, and the distribution of the 7-story buildings is shown in Table 15. According to the data collection of the outpatients building of the Second Hospital of Medical University, the architectural model of the outpatients building of the Second Hospital of Medical University was drawn 1:1 in Revit. The model is $106.21 \mathrm{~m}$ in length, $74.5 \mathrm{~m}$ in width, and $28.70 \mathrm{~m}$ in height. Among them, except for the height of the first floor is $4 \mathrm{~m}$, the height of the remaining floors is $3 \mathrm{~m}$. Figure 13 shows the schematic plan of the building on the first floor and Figure 14 is a schematic diagram of the BIM model of the building.
TABLE 15: Function distribution of each floor.

\begin{tabular}{lc}
\hline Floor & Features \\
\hline Floor -1 & $\begin{array}{c}\text { Supermarket/Pharmacy Warehouse/CT room... } \\
\text { Floor } 1\end{array}$ \\
Floor 2 & $\begin{array}{c}\text { Lobby/Registered clinic/Testing department... } \\
\text { Cardiovascular clinic/Respiratory clinic/Hematology } \\
\text { clinic... }\end{array}$ \\
Floor 3 & $\begin{array}{c}\text { department... } \\
\text { Floor } 4\end{array}$ \\
Floor 5 & Obstetrics and gynecology clinic/Nuclear medicine \\
Floor 6 & Obstetrics and gynecology II ward/Second center \\
operating room...
\end{tabular}

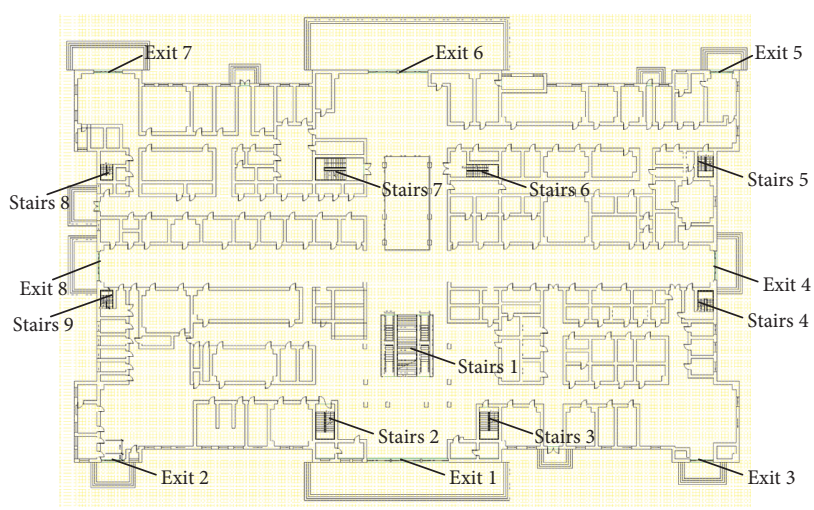

Figure 13: Floor 1 plane structure diagram.

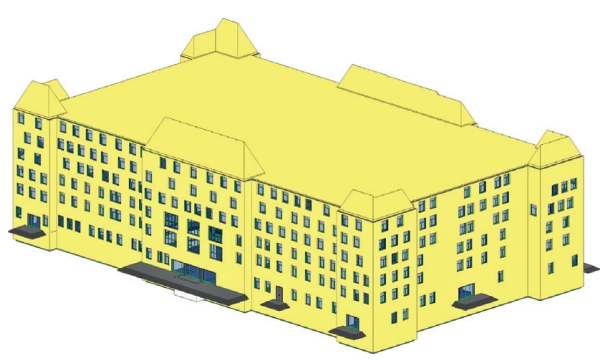

Figure 14: Building information model.

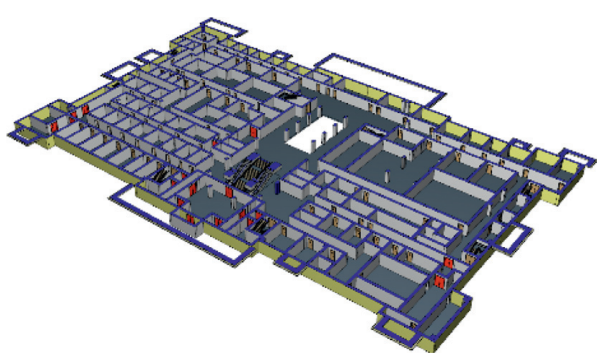

Figure 15: Fire model diagram of floor -1 .

The model of the outpatients building of the Second Hospital of Medical University established by the model in Revit is imported into the fire dynamic simulation software FDS in the format of IFC, and the construction of the FDS 


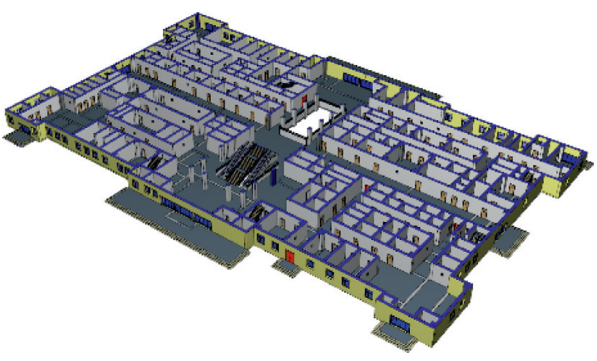

Figure 16: Fire model diagram of floor 1.

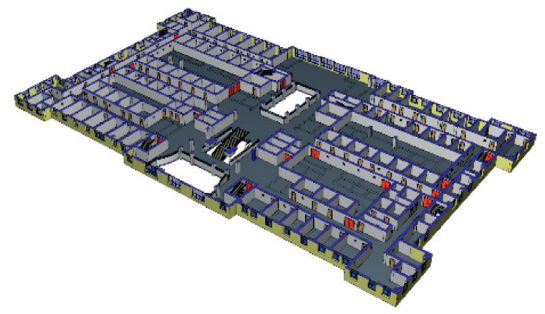

FiguRE 17: Fire model diagram of floor 2.

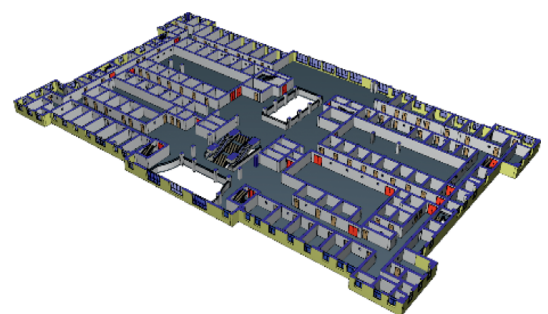

Figure 18: Fire model diagram of floor 3.

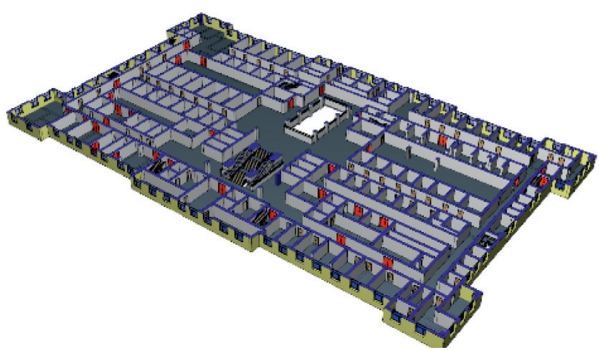

Figure 19: Fire model diagram of floor 4.

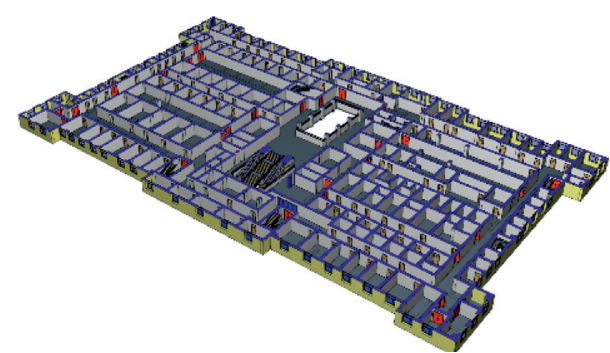

Figure 20: Fire model diagram of floor 5.

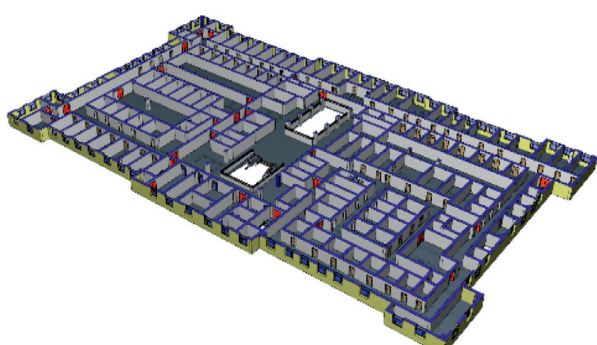

Figure 21: Fire model diagram of floor 6 .

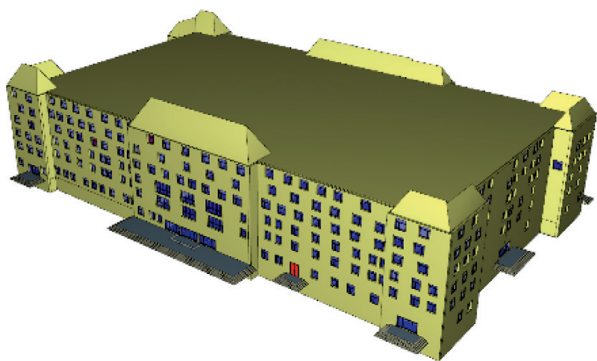

FIgURE 22: Fire model diagram in FDS.

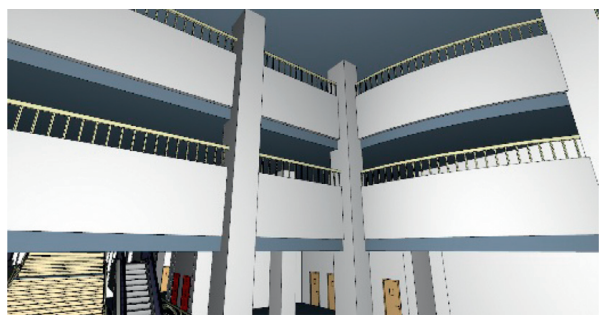

Figure 23: Hall model drawing of floor 1.

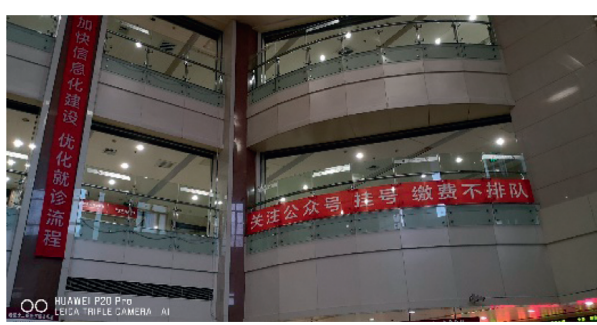

FIgURE 24: Hall actual picture of floor 1.

fire model is completed by adding various parameters such as materials, combustion reactions, and combustibles to FDS. Figures 15-22 show the display effect of the BIM model in FDS. Figure 23 shows the display effect of a certain part of the hospital in the model. Figure 24 shows the actual display effect of this part of the hospital.

3.11. Analysis of Evacuation Dynamic Parameters. By combining data from multiple papers, in this study, the number of evacuees was planned to be 2640. In this study, by 
TABle 16: Reaction time of different pedestrians.

\begin{tabular}{lccr}
\hline & Normal & & Patients \\
\hline Male & $10 \mathrm{~s}$ & Male & $50 \mathrm{~s}$ \\
Female & $20 \mathrm{~s}$ & Female & $60 \mathrm{~s}$ \\
Children & $40 \mathrm{~s}$ & Children & $70 \mathrm{~s}$ \\
Elderly & $40 \mathrm{~s}$ & Elderly & $80 \mathrm{~s}$ \\
\hline
\end{tabular}

TABle 17: Evacuation speed of different pedestrians.

\begin{tabular}{lccc}
\hline & Normal & & Patients \\
\hline Male & $1.15 \mathrm{~m} / \mathrm{s}$ & Male & $1.0 \mathrm{~m} / \mathrm{s}$ \\
Female & $1.03 \mathrm{~m} / \mathrm{s}$ & Female & $0.85 \mathrm{~m} / \mathrm{s}$ \\
Children & $0.95 \mathrm{~m} / \mathrm{s}$ & Children & $0.6 \mathrm{~m} / \mathrm{s}$ \\
Elderly & $0.69 \mathrm{~m} / \mathrm{s}$ & Elderly & $0.5 \mathrm{~m} / \mathrm{s}$ \\
\hline
\end{tabular}

TABle 18: Distribution of pedestrians on each floor.

\begin{tabular}{lcccccccc}
\hline Floor & Male 0 & Male 1 & Female 0 & Female 1 & Elderly 0 & Elderly 1 & Children 0 & Children 1 \\
\hline-1 & 20 & 10 & 20 & 10 & 10 & 10 & 10 & 10 \\
1 & 180 & 90 & 180 & 90 & 135 & 90 & 45 & 15 \\
2 & 60 & 30 & 60 & 30 & 45 & 30 & 30 \\
3 & 60 & 30 & 60 & 30 & 45 & 30 & 15 & 30 \\
4 & 120 & 40 & 40 & 40 & 40 & 80 & 10 & 0 \\
5 & 125 & 25 & 50 & 100 & 10 & 0 & 0 \\
6 & 125 & 25 & 50 & 100 & 10 & 0 & 10 \\
\hline
\end{tabular}

combining the actual departments and functions of the outpatients building of the Second Hospital of Medical University, the staff types were divided into 8 types, namely, male (normal), male (patients), female (normal), female (patients), children (normal), children (patients), elderly (normal), and elderly (patients). Table 16 shows the reaction time of different pedestrians in the fire, and Table 17 shows the evacuation speed of different pedestrians. Through onsite visits to the outpatients building of the Second Hospital of Medical University, combined with the actual functions of each floor of the outpatients building, different staff proportions were set for each floor. The specific staff type ratio distribution is shown in Table 18 below.

\section{Results}

Cheng et al. [51] conducted a risk assessment of pedestrian evacuation in subway stations under large-scale sports activities. Chen et al. [52] synthesized the preevacuation behavior data of the residents obtained through the investigation and discussed the influencing factors of the evacuation time. Choochart and Thipyopas [53] used software Pathfinder to study passenger evacuation of Airbus A330-300 aircraft. de Lama et al. [54] used a virtual environment to study human behavior in fire. Velásquez et al. [55] studied the gait body mass index of building risk assessment through graph theory. This article will combine the research results of various scholars and fire products to conduct the evacuation risk assessment of building fire pedestrians.

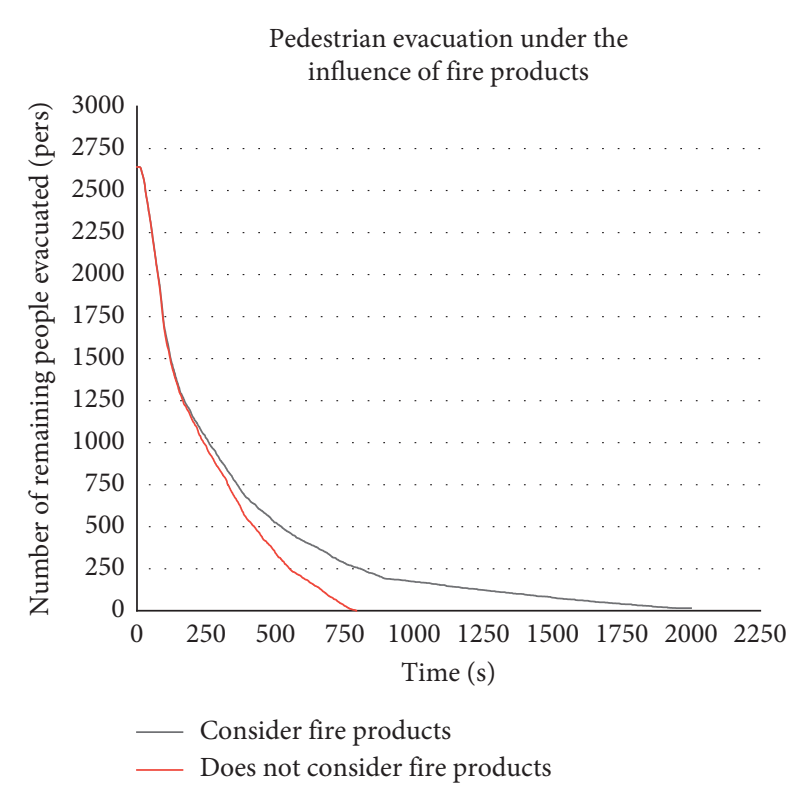

FIgURE 25: Pedestrians evacuation under the influence of fire products.

As shown in the Figure 25, the person has no behavior in the first $10 \mathrm{~s}$, and the person starts to move after $10 \mathrm{~s}$. This is because in all types of pedestrians, the reaction time of healthy men is the shortest, and healthy men begin to escape $10 \mathrm{~s}$ after the fire alarm. It can be seen from the curve that the evacuation curve of the pedestrians in the two scenarios is almost the same in the first $185 \mathrm{~s}$ or so, because the fire 


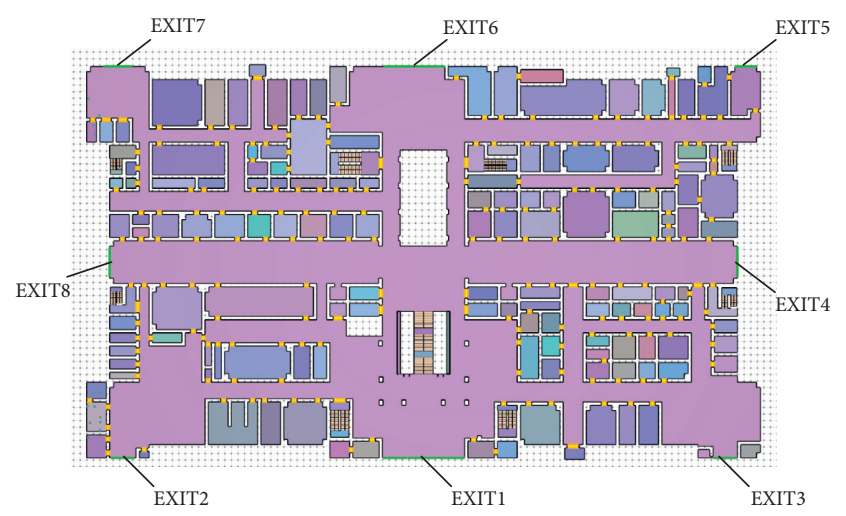

FIGURE 26: Schematic diagram of each exit.

Table 19: Accident level classification.

\begin{tabular}{lcc}
\hline Type of accident & $\begin{array}{c}\text { Number of serious } \\
\text { injuries }\end{array}$ & Number of deaths \\
\hline Particularly serious & 100 pedestrians or & 30 pedestrians or \\
accident & more & more \\
Serious accident & $50-100$ pedestrians & $10-30$ pedestrians \\
Major accident & $10-50$ pedestrians & $\begin{array}{c}3-10 \text { pedestrians } \\
3 \text { pedestrians or } \\
\text { General accident }\end{array}$ \\
\hline
\end{tabular}

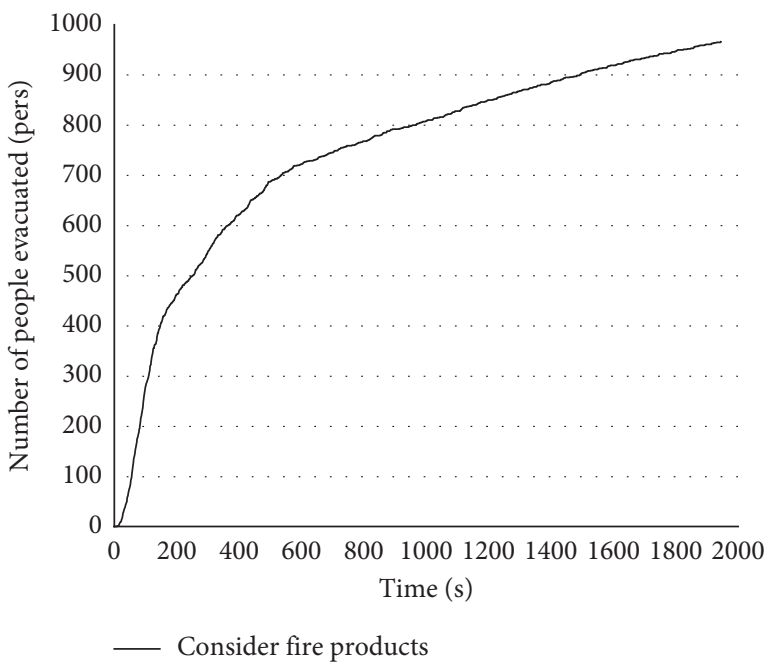

FIgURE 27: Exit 1 evacuation situation.

products in Scenario 2 did not have a great impact on the pedestrians during this period, but in the $185 \mathrm{~s}$. After that, the impact of fire products is getting bigger and bigger, the slope of the curve in Scenario 2 is getting smaller and smaller, and the slope represents the efficiency of pedestrians evacuation per unit time. With the evacuation time, the evacuation time of Scenario 1 is $792.3 \mathrm{~s}$. In the Scenario 2, the evacuation time of the pedestrians was $1946 \mathrm{~s}$ (of which 15 pedestrians failed to evacuate), and the difference between the evacuation results was $145.61 \%$.

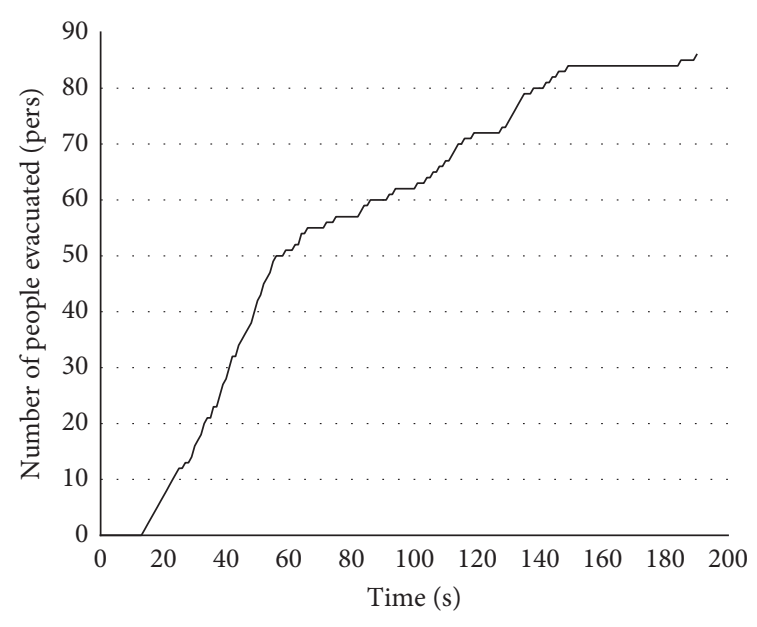

— Consider fire products

Figure 28: Exit 2 evacuation situation.

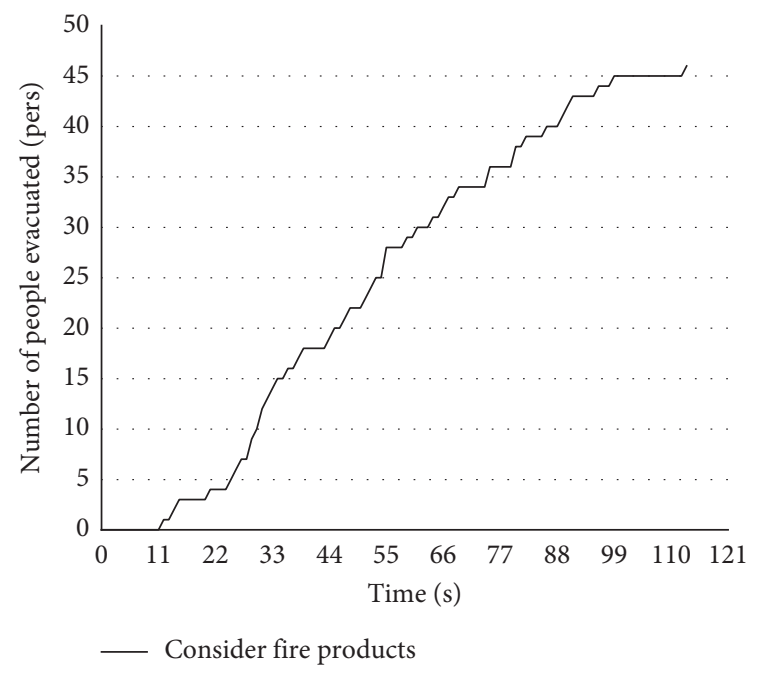

FIgURE 29: Exit 3 evacuation situation.

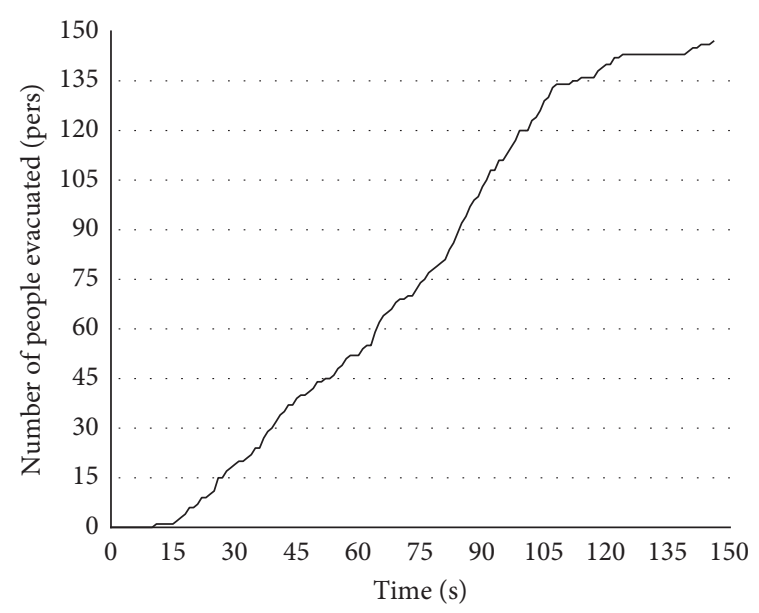

Consider fire products

FIgURE 30: Exit 4 evacuation situation. 


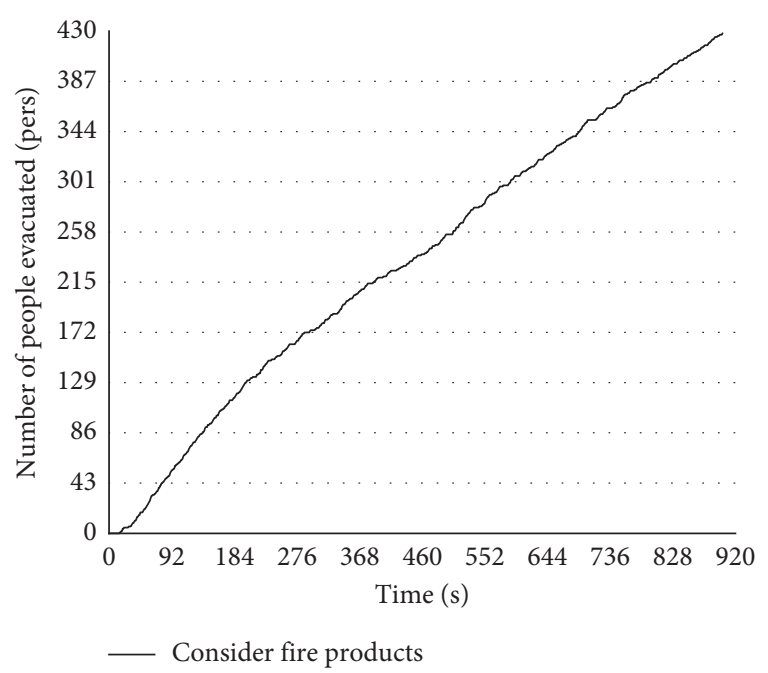

FIgURE 31: Exit 5 evacuation situation.

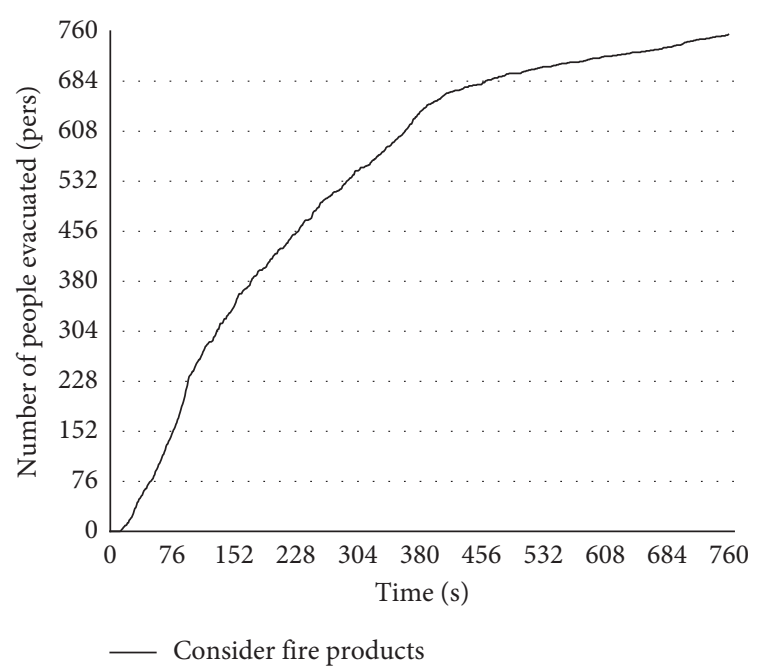

FIgURE 32: Exit 6 evacuation situation.

The specific distribution of the exits is shown in Figure 26. In order to study the evacuation situation and injury degree of pedestrians at each exit, the indicators for judging whether the pedestrians are safe to evacuate from each exit are obtained by combining Tables 10 and 11. Based on the classification of accidents according to the Regulations on Reporting, Investigation and Handling of Production Safety Accidents (State Council Order No. 493 of the People Republic of China), the standards shown in Table 19 were obtained. Combine the data in the Table and the evacuation situation of each exit to determine the degree of injury and the type of accident. As can be seen from Figures 27-34, the pedestrians at the seven exits $1,3,4,5,6,7$, and 8 were not injured during the evacuation process. Before the minor injury, the pedestrians had fled the fire. Through calculation and analysis, the 7 exits had a total of 2539 evacuees, accounting for $96.17 \%$ of the total number.

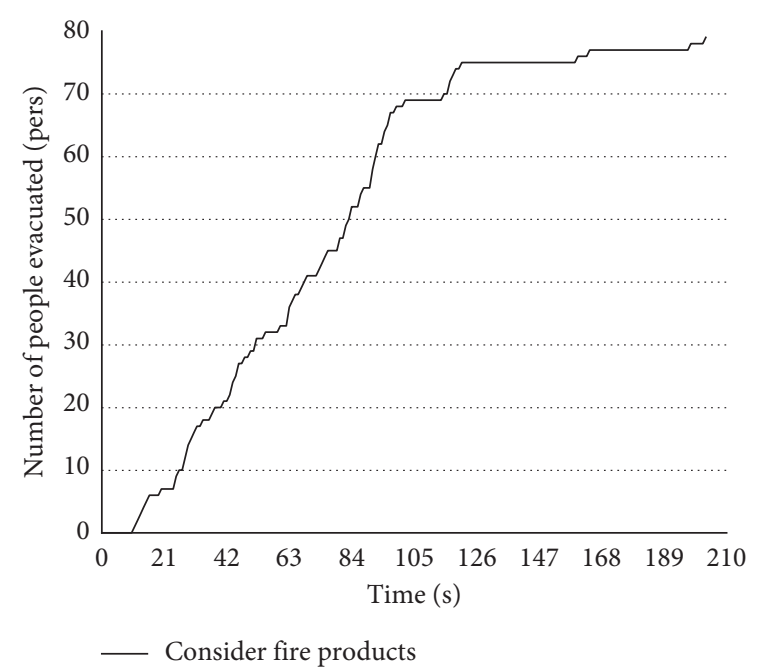

Figure 33: Exit 7 evacuation situation.

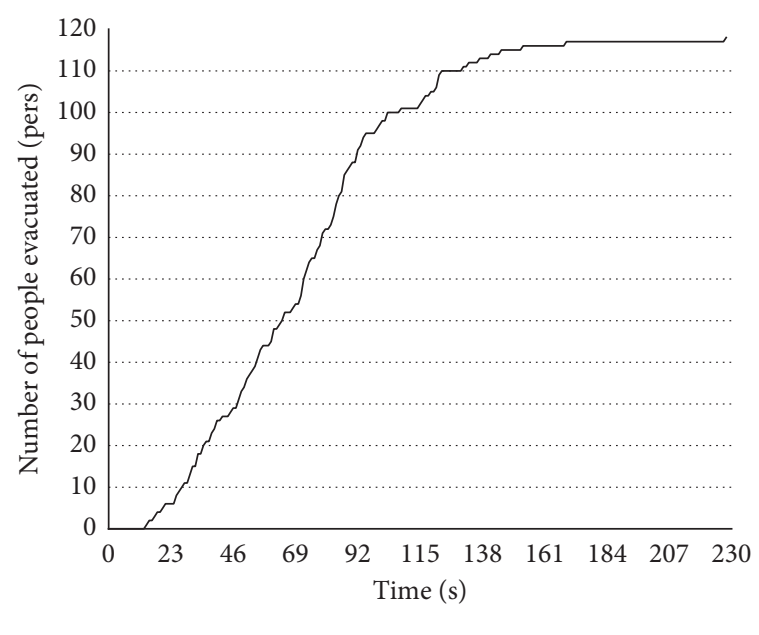

- Consider fire products

FIgUre 34: Exit 8 evacuation situation.

In Exit 2's evacuation situation, 61 pedestrians had fled the fire before ASET1 = $92 \mathrm{~s}$, and the remaining 25 pedestrians began to be injured. At this time, the remaining 25 pedestrians entered a state of minor injury. With the evacuation time, at $190 \mathrm{~s}$, Twenty-five pedestrians with minor injuries escaped from the fire site; the total time from entering the minor injury state to completely escaping from the fire site was $98 \mathrm{~s}$, accounting for $51.58 \%$ of the total evacuation time of the exit. This is because the fire products have a great impact on the evacuation speed of pedestrians; as a result, pedestrians are slow to move. For the same distance, compared with not considering fire products, pedestrians will spend more time to escape under the influence of fire products Figure 35 shows the location of region 12 in pathfinder.

Through the search for data, the reason for the failure of pedestrians evacuation is that the temperature of the regions 1-12 where the pedestrians is located exceeds $120^{\circ} \mathrm{C}$, and 


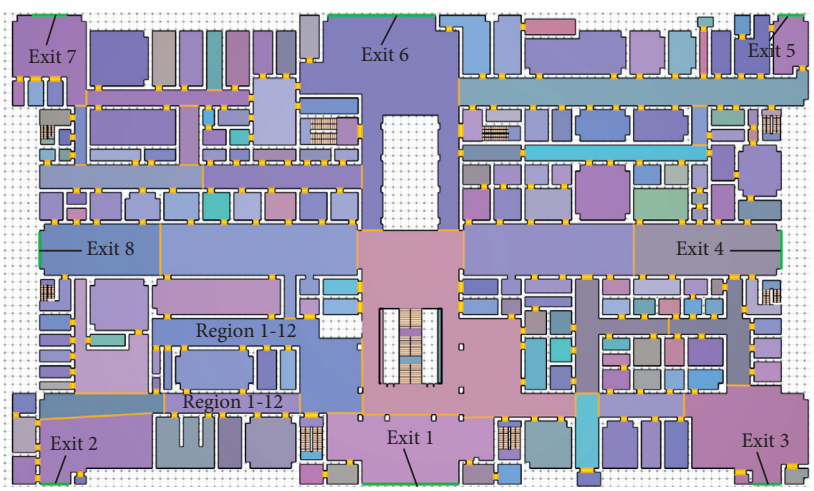

Figure 35: Region 1-12 in pathfinder.

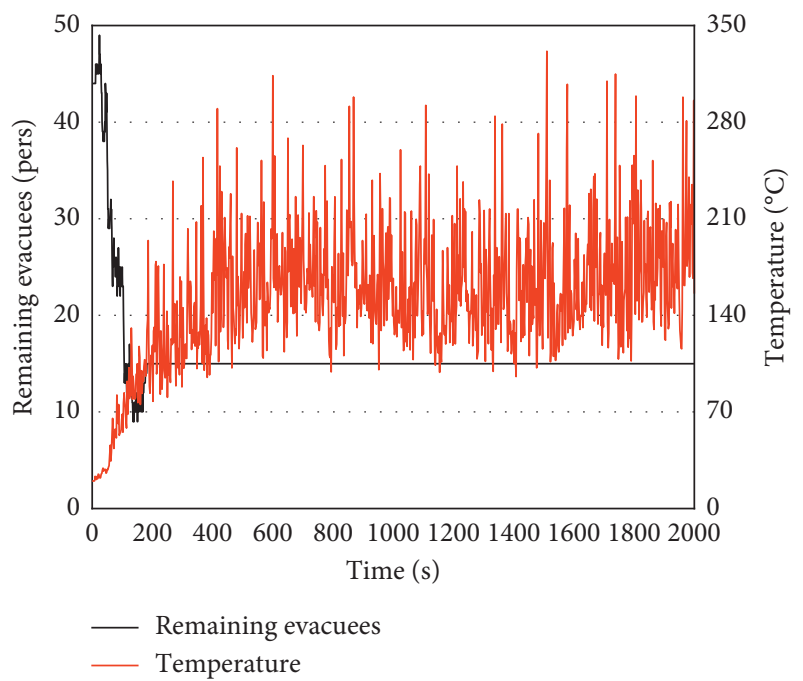

FIgURE 36: Evacuation and temperature changes of pedestrians in region 1-12.

during the development of the fire, the temperature reached the lethal temperature, and the CO did not reach the lethal volume fraction. So this time, the study takes temperature as the research object. As shown in the Figure 36, the fitting curve of the evacuation situation of the regions 1-12 and the temperature change situation. At the $182 \mathrm{~s}, 15$ pedestrians in the region 1-12 because the temperature of the region reached $129.1^{\circ} \mathrm{C}$ and the evacuation coefficient became 0 . That is to say, the 15 pedestrians lost their mobility and entered a comatose state. Without considering any rescue, when $t=186 \mathrm{~s}$, according to the data in Table 11, it can be considered that the temperature reached the lethal state, and these 15 pedestrians went from a severely injured coma to a dead state. According to the information in Table 19, it can be judged that the fire accident is a major accident.

\section{Conclusions}

(1) Compared with traditional research methods, the evacuation time of the evacuation model under the influence of fire products is longer, and the speed of the evacuation will change with time until the evacuation fails. This method is closer to the evacuation result of pedestrians in a real fire sceneIt can be close to the evacuation result of people in the real fire scene.

(2) The spray intensity has little effect on the speed coefficient. In the early and mid-term of the fire, the smaller the spray intensity, the greater the irritation to the human body. This is because the presence of spray leads to a slower temperature rise, which will have a positive effect on evacuation. In the later stage of the fire, the greater the spray intensity, the weaker the influence of the fire products, the longer it takes for the speed coefficient to return to zero, and the more time the personnel will have to escape from the fire.

(3) The smoke exhaust rate has a significant effect on the speed coefficient. This is because the presence of smoke can bring out the fire smoke and high-temperature heat plume, reducing the impact of fire products in the early stage. In the later stage of the fire, the higher the smoke exhaust rate, the more evacuation time is available for personnel, and the effect of smoke exhaust on evacuation is far better than spraying.

\section{Data Availability}

The data used to support the findings of this study are available from the corresponding author upon request.

\section{Conflicts of Interest}

The authors declare that they have no conflicts of interest.

\section{Acknowledgments}

This paper was supported by the National Natural Science Foundation of China (No. 11704090), University Nursing Program for Young Scholars with Creative Talents in Heilongjiang Province (UNPYSCT-2018207), and Fundamental Research Foundation for Universities of Heilongjiang Province (LGYC2018JC048).

\section{References}

[1] W. G. Yan and X. L. Zhang, "Study on effect of people's cognitive level on evacuation psychology and behavior in building fire," Journal of Safety Science and Technology, vol. 6, no. 5, pp. 108-113, 2010.

[2] Y. M. Tian, "On human behavior in fire accidents and computer-simulation methods," Journal of Safety and Environment, vol. 6, no. 5, pp. 26-30, 2006.

[3] W. G. Song, Y. F. Yu, and T. Chen, "Influences of exit conditions on pedestrian evacuation," Fire Safety Science, vol. 12, no. 2, pp. 100-103, 2006.

[4] T. Chen, W. G. Song, W. C. Fan, and S. X. Lu, "The dependence of crossing exit width and personnel blocking and its simulation and analysis," Progress in Natural Science, vol. 14, no. 4, pp. 567-572, 2004. 
[5] J. Q. Ju and D. H. Chen, "Impact of emergency lighting spectrum on evacuation and escape," Light \& Lighting, vol. 30, no. 2, pp. 5-7+28, 2006.

[6] X. P. Rao, "Analysis of passenger flow delay at rail transit station stairs and escalators," Traffic and Transportation, Academic Edition, vol. 1, pp. 13-15, 2005.

[7] P. He and Z. B. Chen, "Feasibility of double escalator as auxiliary evacuation ladder in commercial building," Sichuan Architecture, vol. 5, pp. 36-37, 2006.

[8] United States Department of Commerce National Bureau of Standards, Design and Construction of Building Exits, U.S. GPO, Washington, DC, USA, 1935.

[9] Y. Q. Li, Building Fire Protection Engineering, Chemical Industry Press, Beijing, China, 2004.

[10] J. Pauls, "A personal perspective on research, consulting and codes/standards development in fire-related human behaviour, 1969-1999, with an emphasis on space and time factors," Fire and Materials, vol. 23, no. 6, pp. 265-272, 1999.

[11] L. F. Henderson, "The statistics of crowd fluids," Nature, vol. 229, no. 5284, pp. 381-383, 1971.

[12] Q. Chen and B. Z. Chen, "General behavioral characteristics of people taking refuge in fire," Safety, vol. 1, pp. 39-42, 1997.

[13] M. H. Zhong, W. C. Fan, Q. A. W, and B. Z. Chen, "Research progress of personnel avoidance strategies during fire accidents," Journal of Natural Disaster, vol. 3, pp. 66-71, 1999.

[14] G. Q. Xiao, L. M. Wen, and B. Z. Chen, "Review and perspective in the study of human behavior during evacuation from building fire," China Safety Science Journal, vol. 11, no. 3, pp. 50-54, 2001.

[15] L. M. Wen and B. Z. Chen, "Study on the model of emergency evacuation in case of major accident," China Safety Science Journal, vol. 9, no. 3, pp. 69-73, 1999.

[16] P. H. Zhang and B. Z. Chen, "The behavior law of personnel evacuation during fire," Journal of Northeastern University, vol. 22, no. 1, pp. 54-56, 2001.

[17] P. H. Zhang, B. Z. Chen, and L. Z. Liu, "Study on virtual reality and human emergent evacuation behavior in building fire," China Safety Science Journal, vol. 12, no. 1, pp. 49-53, 2002.

[18] Z. Fang and Z. M. Lu, "A spatial grid model for emergency evacuation from building," China Safety Science Journal, vol. 22, no. 4, pp. 13-16, 2001.

[19] Z. Fang, D. H. Chen, and Z. M. Lu, "Study on the personnel evacuation of movie theater by using computer emulation method," Fire Science and Technology, vol. 2, pp. 18-20, 2002.

[20] Z. Fang, P. Wang, D. H. Chen, J. X. Duan, and Z. R. Hu, "The development of evaluation software of safety evacuation for high buildings," Fire Science and Technology, vol. 5, pp. 439-442, 2004.

[21] W. G. Song, Y. F. Yu, W. C. Fan, and H. P. Zhang, “A cellular automata evacuation model considering friction and repulsion," Science in China Series E, vol. 48, no. 4, p. 403, 2005.

[22] L. Z. Yang, W. F. Fang, R. Huang, and Z. H. Deng, "Model of personnel escape in fire based on cellular automata," Chinese Science Bulletin, vol. 47, no. 12, pp. 896-901, 2002.

[23] L. Z. Yang, J. Li, D. L. Zhao, W. F. Fang, and W. C. Fan, "Micro-discrete model of personnel evacuation based on individual behavior," Science in China Series E, vol. 11, pp. 1264-1270, 2004.

[24] Y. Zheng, X.-G. Li, B. Jia, and R. Jiang, "Simulation of pedestrians' evacuation dynamics with underground flood spreading based on cellular automaton," Simulation Modelling Practice and Theory, vol. 94, pp. 149-161, 2019.

[25] M. Choi and S. Chi, "Optimal route selection model for fire evacuations based on hazard prediction data," Simulation Modelling Practice and Theory, vol. 94, pp. 321-333, 2019.
[26] G. Q. Chu, J. H. Sun, Q. S. Wang, and S. N. Chen, "Simulation of the effect of evacuation preparation time and exit width on personnel evacuation," Chinese Science Bulletin, vol. 51, no. 6, pp. 738-744, 2006.

[27] Q. J. Tong, G. F. Quan, and L. Shao, "Analysis of mentality and behavior of people involved in fire disasters," Journal of Hefei University of Technology (Social Sciences), vol. 18, no. 9, pp. 159-162, 2004.

[28] S. B. Liu, Experiment and Simulation of Individual and Crowd Evacuation Behavior, University of Science and Technology of China, Hefei, China, 2010.

[29] W. G. Song, J. Ma, F. N. Yuan, H. Y. Zheng, and Z. M. Fang, "On students' response characteristic to exit signs: a primary study," Fire Safety Science, vol. 15, no. 3, pp. 159-169, 2006.

[30] G. M. Zhao and Y. F. Zhao, "Simulation on fire safety evacuation optimization about university gymnasium," Fire Science and Technology, vol. 11, pp. 1440-1442, 2015.

[31] J. X. Li, "Research on evacuation prediction model about classroom building fire," Journal of Yichun College, vol. 4, pp. 21-23+28, 2009.

[32] Z. M. Chen, R. Huo, H. B. Wang, and D. Y. Zeng, "Personal evacuate time prediction in a building fire," Fire Safety Science, vol. 12, no. 1, pp. 40-45, 2003.

[33] L. M. Yuan and W. C. Fan, "Theoretical analysis on the development law of hot smoke layer in large space building fire," Journal of Natural Disasters, vol. 7, no. 1, pp. 23-28, 1998.

[34] F. Liu, W. Zhu, and G. X. Wang, "Biological toxicity effect of CO in fire smoke," Journal of Chongqing University, vol. 32, no. 5, pp. 577-581, 2009.

[35] G. Q. Chu and J. H. Wang, Risk Assessment for Occupant Evacuation in Building Fires, pp. 59-60, Science Press, Beijing, China, 2017.

[36] C. Sun, Y. C. Liu, B. Wang, and Y. Q. Jiang, "Numerical simulation of fire spread and evacuation for teaching building," Journal of Harbin University of Science and Technology, vol. 23, no. 5, pp. 106-112, 2008.

[37] Y. Song, S. G. Chen, S. J. Lan, and K. Yang, "Simulation study on fire evacuation from airport terminal," China Safety Science Journal, vol. 28, no. 8, pp. 31-36, 2018.

[38] Y. Chen, Research on Emergency Management in the Subway Station Based on BIM, M.S. Thesis, Shijiazhuang Tiedao University, Shijiazhuang, China, 2018.

[39] S. S. Liu, H. Y. Ma, and Y. Y. Jiao, "Study on personal evacuation from high-rise building in fire," Fire Science and Technology, vol. 38, no. 6, pp. 794-798, 2019.

[40] Y. Li and Y. Zhang, "Study on fire simulation and safety evacuation of connected dormitory buildings," Journal of Safety Science and Technology, vol. 15, no. 1, pp. 163-168, 2019.

[41] S. M. Zhu, Composite Simulation of Building Evacuation Based on Fire Two-Zone Model, M.S. Thesis, Central South University, Changsha, China, 2010.

[42] K. Fridolf, D. Nilsson, H. . Frantzich, E. Ronchi, and S. Arias, "Walking speed in smoke: representation in life safety verifications," in Proceedings of the 12th International Conference on Performance Based Codes and Fire Safety Design Methods, Oahu, HI, USA, 2018.

[43] J. A. Milke, "Evaluating the early development of smoke hazard from fires in large spaces," ASHR AE Transaction, vol. 106, pp. 627-636, 2000.

[44] H. Z. Zhao and C. Qian, "Research on inhibiting effect of water spraying on fire suppression of high-rise buildings façade," Journal of North China University of Science and Technology: Natural Science Edition, vol. 32, no. 5, pp. 577581, 2019. 
[45] H. T. Khoat, J. T. Kim, T. D. Quoc, J. H. Kwark, and H. S. Ryou, "A numerical analysis of the fire characteristics after sprinkler activation in the compartment fire," Energies, vol. 13, no. 12, p. 3099, 2020.

[46] P. P. Yang, B. M. Shi, and C. M. Mu, "Study on influence of water sprinkler on fire characteristic parameters in dormitory fire based on numerical simulation," Journal of Safety Science and Technology, vol. 8, no. 5, pp. 25-28, 2012.

[47] Y. H. Wang, K. Y. Li, H. P. Zhang, and Z. J. Lu, "Numerical investigation on smoke spreading character under sprinkler spray in building corridor," China Safety Science Journal, vol. 20, no. 5, pp. 62-66, 2010.

[48] R. X. Sun and B. Yao, "Numerical simulation on extinguish effect of water mist system in urban underground utility tunnel," Fire Safety Science, vol. 28, no. 3, pp. 29-34, 2019.

[49] J. G. Wang, J. K. Sun, J. Z. Zhang, and Y. Li, "Study on numerical simulation of smoke emission in corridor under different smoke exhaust rate," Fire Science and Technology, vol. 37, no. 12, pp. 1465-1468, 2018.

[50] Y. Zhu and S. C. Li, "Smoke exhausting efficiency from corridor of high-rise building vs coupled factors," China Safety Science Journal, vol. 29, no. 2, pp. 76-81, 2019.

[51] Z. Cheng, J. Lu, and Y. Zhao, "Pedestrian evacuation risk assessment of subway station under large-scale sport activity," International Journal of Environmental Research and Public Health, vol. 17, no. 11, p. 3844, 2020.

[52] J. Chen, J. Yu, J. Wen et al., "Pre-evacuation time estimation based emergency evacuation simulation in urban residential communities," International Journal of Environmental Research and Public Health, vol. 16, no. 23, p. 4599, 2019.

[53] P. Choochart and C. Thipyopas, "Study of passenger evacuation from the Airbus a330-300 aircraft," Proceedings, vol. 39, no. 1, p. 25, 2019.

[54] C. De Lama, C. González-Gaya, and A. Sánchez-Lite, "An experimental test proposal to study human behaviour in fires using virtual environments," Sensors, vol. 20, no. 12, p. 3607, 2020.

[55] W. Velásquez, M. S. Alvarez-Alvarado, A. Munoz-Arcentales, S. López-Pernas, and J. Salvachúa, "Body mass index in human gait for building risk assessment using graph theory," Sensors, vol. 20, no. 10, p. 2899, 2020. 